\title{
Effect of Water Velocity on the Timing of Skeletogenesis in the Arctic Charr, Salvelinus alpinus (Salmoniformes: Teleostei): An Empirical Case of Developmental Plasticity
}

\author{
Richard Cloutier, ${ }^{1}$ Alain Caron, ${ }^{1}$ Thomas Grünbaum, ${ }^{1}$ and Nathalie R. Le François ${ }^{1,2}$ \\ ${ }^{1}$ Laboratoire de Biologie évolutive, Université du Québec à Rimouski, Rimouski, QC, Canada G5L 3A1 \\ ${ }^{2}$ Biodôme de Montréal, Montréal, QC, Canada H1V $1 B 3$ \\ Correspondence should be addressed to Richard Cloutier, richard_cloutier@uqar.qc.ca
}

Received 25 October 2010; Accepted 2 December 2010

Academic Editor: Eugene S. Morton

Copyright ( $) 2010$ Richard Cloutier et al. This is an open access article distributed under the Creative Commons Attribution License, which permits unrestricted use, distribution, and reproduction in any medium, provided the original work is properly cited.

\begin{abstract}
Phenotypic plasticity has been demonstrated in fishes but rarely addressed with respect to skeletogenesis. The influence of water velocity on the sequence of chondrification and ossification is studied for the median fins of Arctic charr, Salvelinus alpinus, during a period of 90 days post hatching. Time of appearance, relative position within sequences, and direction of development among serially repeated elements are compared between two velocity treatments. Water velocity has induced changes in the timing of events and to a lesser extent on the relative sequence events in the locomotor system. Ossification is more responsive to water velocity than chondrification, and early-forming elements are less responding than late-forming elements. Directions of development are fairly conservative. It is suggested that a faster sustained swimming (behavioural adaptation to a higher water velocity) could induce differential mechanical stresses on developing skeletal elements involved in locomotion and therefore induce changes primarily in the timing of the ossification.
\end{abstract}

\section{Introduction}

Developmental sequences are known to be controlled genetically as well as constrained environmentally $[1,2]$. A specific type of developmental sequence, the sequences of chondrification and ossification, has been investigated in a large diversity of fishes [3-13], amphibians [14-19], reptiles (including birds) [20-28], and mammals [29-32]; both sequences refer to the specific ontogenetic order in which anatomical cartilaginous and bony structures appear during the early development of vertebrates. Information derived from such sequences could be used to validate homology $[12,13,33]$ and phylogenetic position $[14,20]$, and to infer evolutionary developmental patterns and processes (e.g., heterochrony) $[11,29,30,32,34,35]$.

It has been suggested that ossification sequences conform to functional needs $[29-31,35,36]$. In a general way, structures that are required functionally earlier during development will ossify earlier in the sequence although inconsistencies may occur $[3,37,38]$. Among the functional requirements most influential on the ossification, locomotion has been shown to induce differential mechanical stress, which may change the shape, size, or toughness of the bones [39-42]. In order to understand if the observed patterns of ossification are the result of processes controlled genetically or developmentally, as well as a response to environmental constraints, experimental studies on living fish morphology are of primary interest.

The effects of many environmental parameters (e.g., $\mathrm{pH}$, temperature, salinity, and water viscosity) have been tested experimentally on the early development of larval and juvenile fishes from hatcheries and wild stocks. It has long been known that experimental changes in temperature, photoperiod and salinity affect the meristic count of serial (or iterated) bones such as fin rays and vertebrae [43, 44]. However, studies that have shown an experimental effect 
on the timing of ossification have mainly focused on temperature [35, 45-48]. Pavlov and Moksness [46] demonstrated that wolffish Anarhichas lupus incubated at higher temperature exhibited morphological modifications of the axial and appendicular skeleton (e.g., fused hypurals, fused epurals, and absence of distal radials and fin rays in median fins). Mabee et al. [35] also tested the effect of temperature during incubation and rearing periods of the zebrafish Danio rerio and the Siamese fighting fish Betta splendens. They found out that there was no significant temperature effect on the sequence of ossification, or only minor variation in the sequence. However, they observed that fishes incubated and reared at higher temperature were characterised with higher levels of intraspecific variation in iterated cranial bones (e.g., infraorbitals, branchial arch bones, and branchiostegal rays) and in cartilage bones (preformed in a cartilaginous template sensu Patterson [49]). Campinho et al. [48] studied the sensitivity of chondrification and ossification to temperature in the Mozambique tilapia Oreochromis mossambicus. They found that the sequence of ossification and rate at which it occurred is more sensitive to temperature than is chondrogenesis. Sequences of chondrification and ossification in $O$. mossambicus were not altered by temperature. All previous studies investigated different responses of the ossification (primarily) to a temperature treatment during the early development. However, no study evaluating the effect of water velocity on the early chondrification and ossification of fishes has been published.

According to Davison's [50] review on the effect of exercise training on fish, most of the literature deals with food conversion ratio, social behaviour, growth rate, and physiology. Azuma [51] and Azuma et al. [52] have demonstrated that juvenile masu salmon Oncorhynchus masou masou reared in higher flow speed had a better growth profile after c. 100 days. Furthermore, the effects of water velocity (in natural and laboratory conditions) on the plasticity of salmonid body size and shape have been investigated in a few salmonid species [36, 53-59]. All of these studies have shown significant effect of water velocity on size and differentially on shape. Water velocity is one of the most limiting environmental factors regulating the distribution and viability of larval fishes. Different types of larval behaviour (limited to high mobility) are associated with different environments subjected to flow variation [60]. Developmental patterns are known to reflect adaptive escape behaviour in fishes in order to optimize survival [61] and are thus hypothesized to be maintained in the course of evolution. Changes of velocity are hypothesized to modify mechanical stress imposed on the locomotor system, pointing to the usefulness of studying the development of the postcranial system under differential water velocities in the laboratory.

In the present study, we test the influence of water velocity during rearing in the Arctic charr, Salvelinus alpinus. The effect of water velocity on the sequence of chondrification and ossification (i.e., timing, order, and direction of formation among elements) is investigated for the dorsal, anal, and caudal fins, which are three major morphological systems associated with fish locomotion. Patterns of chondrification and ossification will be analyzed in terms of absolute and relative timing, rank shift variation, and direction of formation (i.e., uni- or bidirectionally) among serially repeated elements (e.g., radials, hypurals, and caudal vertebrae).

\section{Materials and Methods}

Fertilized Arctic charr, Salvelinus alpinus, eggs used for this experiment originated from the Centre Aquacole Marin de Grande-Rivière from their captive Nauyuk strain broodstock popolation ( 1 female $\times 1$ male).

2.1. Rearing Conditions. Incubation temperature was fixed at $5^{\circ}-6^{\circ} \mathrm{C}$ (with $85 \%$ survival during incubation). At hatching, fry were initially kept in the incubation trays for part of the yolk absorption period, and, afterwards, 500 fish were transferred to the rearing units where the water temperature was raised gradually from $6^{\circ} \mathrm{C}$ to $9^{\circ} \mathrm{C}\left(0.5^{\circ} \mathrm{C}\right.$ per day $)$ and kept constant for the duration of the experiment (90 days). When the absorption phase was completed, first feeding was initiated using enriched artemia and formulated feed to ensure proper food intake of both experimental treatments despite different water flow through the experimental units. Enriched artemia (500 artemia $\mathrm{L}^{-1} \mathrm{~min}^{-1}$ ) supplementation was stopped after 14 days, at which time inert food ingestion was generally acquired. Fish were fed manually to satiety four times a day. The experimental units were low volume raceways ( $20 \mathrm{~cm}$ wide $\times 60 \mathrm{~cm}$ long $\times 15 \mathrm{~cm}$ high $)$ with individual oxygen supply. Water inflow was dechlorinated and UV treated. Mortality, temperature, and dissolved oxygen were monitored twice a day. Overall mortality was low at less than $1 \%$. Photoperiod condition followed a constant cycle $12: 12$ (L:D).

2.2. Experimental Design. The original design of the experiment took into account water flow rate rather than water velocity. The water flow, kept constant throughout the experiment, was fixed at $2 \mathrm{~L} \mathrm{~min}^{-1}$ in treatment $\mathrm{S}$ (slow) and at $6 \mathrm{~L} \mathrm{~min}^{-1}$ in treatment $\mathrm{F}$ (fast); the optimal rearing condition of $S$. alpinus being $6 \mathrm{~L} \mathrm{~min}^{-1}$ [62]. Velocities were calculated with a flowmeter SonTek ATV. Three depth measurements were taken for each treatment: (1) half the water depth in the centre of the unit, (2) half the water depth where the alevins used to gather, and (3) at the location where the alevins used to gather. The average velocity for the current in treatment $\mathrm{S}\left(2 \mathrm{~L} \mathrm{~min}^{-1}\right)$ was $0.37733 \mathrm{~cm} \mathrm{~s}^{-1}$, whereas for treatment $\mathrm{F}\left(6 \mathrm{~L} \mathrm{~min}^{-1}\right)$ it was $0.50629 \mathrm{~cm} \mathrm{~s}^{-1}$.

2.3. Specimens Examined. For each treatment, two individuals were sampled every other day from 2 to 90 days post hatching (dph). The fixation of alevins follows Mabee's [63] protocol. A total of 33 individuals per treatment ranging from $2 \mathrm{dph}\left[\right.$ c. $13 \mathrm{~mm}$ total length $\left.\left(L_{T}\right)\right]$ to $90 \mathrm{dph}(c .28 \mathrm{~mm}$ $L_{T}$ ) were cleared and double stained for cartilage and bone [64]. The total length $\left(L_{T}\right)$ and standard length $\left(L_{S}\right)$ were measured with an ocular micrometer.

2.4. Anatomical Nomenclature. Nomenclature for the appendicular and axial skeletons follows that of Arratia and 
Schultze [44], Arratia et al. [65], and Grünbaum and Cloutier [33]. The caudal fin involves all the elements posterior to neural spine of the preural centrum 2 (i.e., corresponding to the neural spine associated with the second preural caudal vertebra) inclusively [44]. The dorso-caudal lepidotrichia are located dorsally to the notochord articulating with the epurals, in contrast to the ventro-caudal lepidotrichia located ventrally to the notochord and articulating with the haemal spines, parhypural, and hypurals.

2.5. Determination of Developmental Sequences. Individuals were examined and scored under a stereodissecting Wild MZ9.5 microscope. A structure was considered to be forming or ossified when it uptakes the stain (Alcian blue for cartilage and Alizarin red S for bone). Chondrification and ossification sequences are defined in terms of successive events. A chondrification event corresponds to the appearance of a single cartilaginous element. An ossification event corresponds to the ossification of one cartilaginous precursor as well as the direct ossification of an element.

Patterns of chondrification and ossification for 70 endoskeletal elements including the proximal and distal radials of the dorsal and anal fins, and the hypurals, epurals, uroneurals, and vertebrae of the caudal fin are determined plus the ossification patterns of the fin rays of all fins. Chondrification and ossification sequences were described in terms of three major components: (1) the absolute timing (in terms of $\mathrm{dph}$ ) which provides the temporal sequence of appearance of the elements (cartilages and bones), (2) the temporal information converted to relative timing, or the sequential order of formation of these structures, and (3) when dealing with serially repeated elements, direction of chondrification or ossification (i.e., antero-posteriorly, postero-anteriorly, and bidirectional with respect to the body axis) is inferred. Sequences of chondrification and ossification are compared between treatments in terms of (1) the time of first appearance of an element, (2) the relative timing within morphological units (i.e., dorsal, anal, and caudal fins defined by their anatomical boundaries and respective elements), and (3) the direction of chondrification and ossification among serial elements within morphological units.

2.6. Statistical Analyses. Simple linear regressions were used to describe the relationship between log-transformed length $\left(\log _{10} L_{T}\right.$ and $\left.\log _{10} L_{S}\right)$ and age $(\mathrm{dph})$. Analysis of covariance (ANCOVA) was used to compare growth between treatments.

Water velocity treatment might have an effect on the timing of a developmental event and on the order of an event in a sequence. Changes in the order might also imply changes in the direction of formation of serial elements. Differences in the timing of first appearance (in dph) between treatments were calculated for each skeletal element composing the three median fins. Parametric one-sample $t$ tests were used to compare the mean difference in absolute timing of appearance of skeletal element in each fin between treatments with a theoretical value of zero (no treatment effect). The relative timing of events was investigated by attributing a rank value to each event in each sequence. For instance, the five hypothetical elements A-E are forming in the following sequence of events $[\mathrm{E}-\mathrm{B}-(\mathrm{A}$ and $\mathrm{C})$ - D]: E appears first, followed by B, then A and C form simultaneously and finally $\mathrm{D}$ is the last element to form (i.e., $\mathrm{D}$ is the last event of the sequence). The sequence is then composed of five events with two events being simultaneous. The rank value of each event is then scored as follows: $\mathrm{E}$ is the first element to form defining an event with a rank value of 1 . Element $B$ is the second event in the sequence; its rank value is then 2. As elements $A$ and $\mathrm{C}$ have simultaneously formed, their order as events within the sequence cannot be discriminate. Indeed, $\mathrm{A}$ and $\mathrm{C}$ are the 3 rd or 4 th and vice versa. Then, both events are each ranked as 3.5 and finally the last element $\mathrm{D}$ is the 5 th event within the sequence and is consequently ranked as 5. Equal rank was readjusted according to the procedure of Dagnelie [66]. The almost synchronous appearance of elements might also be an artifact of coarse sampling. Spearman rank correlation coefficients are used in order to compare the concordance between sequences [7]. For the purpose of chondrification and ossification sequences, rank comparisons between only those elements with a cartilaginous precursor and a corresponding ossified bone were integrated into the analysis. Statistical analyses were performed using SYSTAT version 10 and SAS 9.1.3.

\section{Results}

3.1. Growth. A linear model best described the relationship between the age and $\log _{10} L_{T}\left(n=26\right.$; Treatment $\mathrm{S}: R^{2}=$ 0.7905; Treatment F : $\left.R^{2}=0.9090\right)$ and $\log _{10} L_{S}(n=26$; Treatment $\mathrm{S}: R^{2}=0.7944$; Treatment $\mathrm{F}: R^{2}=0.8877$ ) for the 90 dph period. Regression lines do not differ significantly between treatments (ANCOVA: $\log _{10} L_{T}: F_{1,51}=1.12 ; P=$ .2958; $\left.\log _{10} L_{S}: F_{1,51}=0.28 ; P=.6014\right)$.

3.2. Median Fin Anatomy. The dorsal fin is composed of 13 proximal radials and 12 distal radials (Figures $1(\mathrm{a})$ and $1(\mathrm{~d})$ ); occasionally a small 14 th proximal radial is formed. The first proximal radial is not associated with a distal radial; rarely, the second proximal radial lacks a distal radial. The first and second proximal radials are short and relatively straight. The distal end of proximal radials $4-13$ is curved posteriorly. The first and second proximal radials are shorter than the remaining radials. The distal radials are small and grossly rounded. In some individuals, proximal radials 1 and 2, and proximal radials 12 and 13 show fusion of their proximal parts (i.e., innermost part within the body). The dorsal fin includes $c$. 14-16 lepidotrichia.

The general anatomy of the anal fin is similar to that of the dorsal fin. The supports of the anal fin include 1213 proximal radials and 11-12 distal radials (Figures 1(b) and $1(\mathrm{~d}))$. In some individuals, proximal radial 6 and 12 are poorly developed. The first and second proximal radials are not associated with a distal radial. Similarly to the distal radials of the dorsal fin, the anal distal radials are small and rounded. Proximal radial 12 is occasionally associated with two or three distal radials. Fusions of proximal parts are 


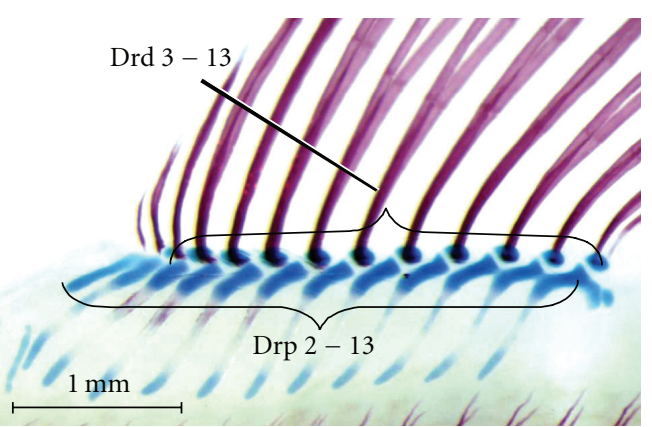

(a)

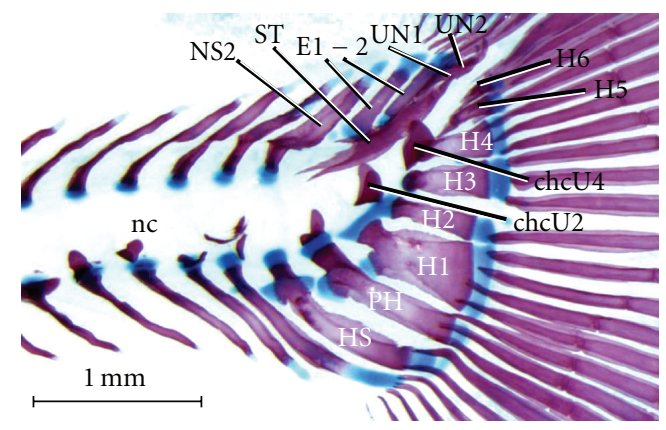

(c)

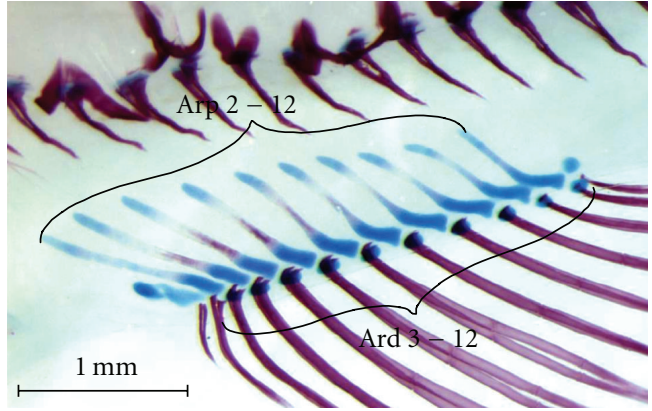

(b)

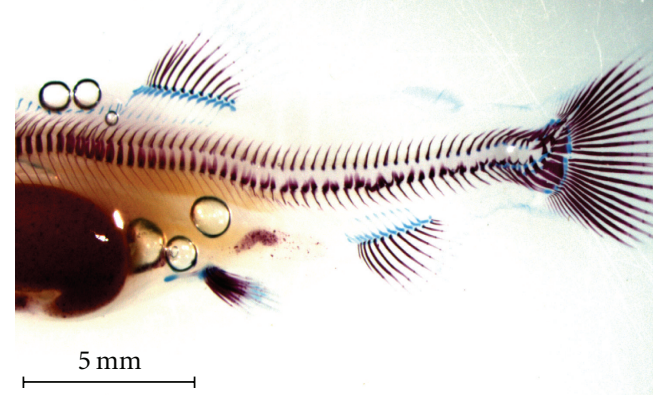

(d)

Figure 1: Anatomy of the postcranial skeleton in juvenile Salvelinus alpinus (d). Details of the dorsal (a), anal (b) and caudal fins (c). Cartilages are stained with Alcian blue and bones with Alizarin red-S. Individual in (a) $-(\mathrm{c})$ is $78 \mathrm{dph}$ old $\left(L_{S}=25.72 \mathrm{~mm}\right)$ and in $(\mathrm{d})$ is 64 dph old $\left(L_{S}=28.39 \mathrm{~mm}\right)$.

relatively frequent between proximal radials 1 and 2, 8 and 9, 9 and 10, 10 and 11 , and 11 and 12 . Approximately 13-15 lepidotrichia are associated with the anal fin.

The anatomy of the caudal fin includes, dorsal to the notochord, the neural arches and spines of preural centra 1 and 2, two epurals, two uroneurals, and the stegural (Figures $1(\mathrm{c})$ and $1(\mathrm{~d}))$. Ventrally, the elements are the haemal arches and spines, the parhypural (= hypural 1 of Vladykov [67]), and a series of six hypurals (= hypurals 2-7 of Vladykov [67]). Finally, surrounding the notochord, we coded for one preural centrum (i.e., preural centrum 1, PU1) and two ural chordacentra (chcU2, 4-6). As mentioned by Arratia and Schultze [44], for Salvelinus spp., ural centrum 2 articulates mainly with hypural 2 whereas ural centrum 4 articulates with hypural 4 . Ural chordacentra 5 and 6 are not present in all individuals but are nevertheless included in the sequence of ossification. When present ural chordacentra 5 and 6 are poorly developed and articulate with their respective hypurals. Two sets of lepidotrichia compose the caudal fin: 5-7 dorso-caudal lepidotrichia and 26-27 ventro-caudal lepidotrichia.

3.3. Time of First Appearance for an Element. The time of first chondrification and ossification is provided for each element of the dorsal and anal fins (Figure 2) and the caudal fin (Figure 3) with the exception of their fin rays for both treatments during the 90 days of experiment. The general pattern of skeletogenesis for the dorsal and anal fins is similar (Figure 2). The chondrification of the dorsal and anal fins is primarily taken into account during the time of the experiment whereas it is primarily the ossification pattern of the caudal fin that occurs during the same period (Figure 3).

Cartilaginous elements are present in the three median fins as early as $2 \mathrm{dph}$. With respect to the caudal and anal fins, more cartilaginous elements are present at day 2 in treatment $S$ than in treatment $F$. All cartilaginous precursors form between 2 and $86 \mathrm{dph}$ in treatment $S$ whereas they form between 2 and $80 \mathrm{dph}$ in treatment $\mathrm{F}$. The completion of the cartilaginous skeleton is achieved earlier for the three fins in treatment $\mathrm{F}$.

Most elements ossified between 26 and $90 \mathrm{dph}$, with the exception of the dorsal distal radials and anal distal radials that ossify later than 90 days (Figure 2). The caudal fin is the first of the three fins to ossify some elements (e.g., $26 \mathrm{dph}$, haemal spine 2, hypurals 1-4 and parhypural) followed by the dorsal (58 and $52 \mathrm{dph}$ for treatments $\mathrm{S}$ and $\mathrm{F}$, resp.) and anal fin (62 and $54 \mathrm{dph}$ for treatments $\mathrm{S}$ and $\mathrm{F}$, resp.) (Figures 2 and 3 ).

Figure 4 compares the time of first appearance between the two treatments for all cartilaginous $(n=65$; Figure $4(\mathrm{a}))$ and ossified elements $(n=45$; Figure $4(\mathrm{~b}))$ of the three median fins simultaneously. Elements figuring above the synchrony line are those forming in treatment $S$ before treatment F (21 cartilaginous and 6 ossified elements), the elements on the line are those appearing simultaneously in both treatments (30 cartilaginous and 10 ossified elements), whereas the elements below the line form earlier in treatment $\mathrm{F}$ than in treatment S (14 cartilaginous and 28 


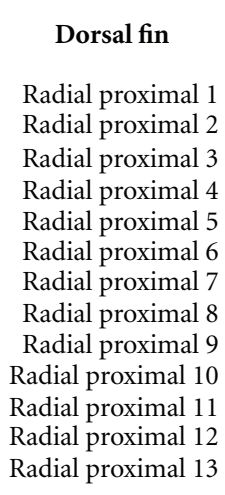

Radial distal 2

Radial distal 3

Radial distal 4

Radial distal 5

Radial distal 6

Radial distal 7

Radial distal 8

Radial distal 9

Radial distal 10

Radial distal 11

Radial distal 12

Radial distal 13

\section{Anal fin}

Radial proximal 1 Radial proximal 2 Radial proximal 3 Radial proximal 4 Radial proximal 5 Radial proximal 6 Radial proximal 7 Radial proximal 8 Radial proximal 9 Radial proximal 10 Radial proximal 11 Radial proximal 12

Radial distal 3 Radial distal 4 Radial distal 5 Radial distal 6 Radial distal 7 Radial distal 8 Radial distal 9 Radial distal 10 Radial distal 11 Radial distal 12
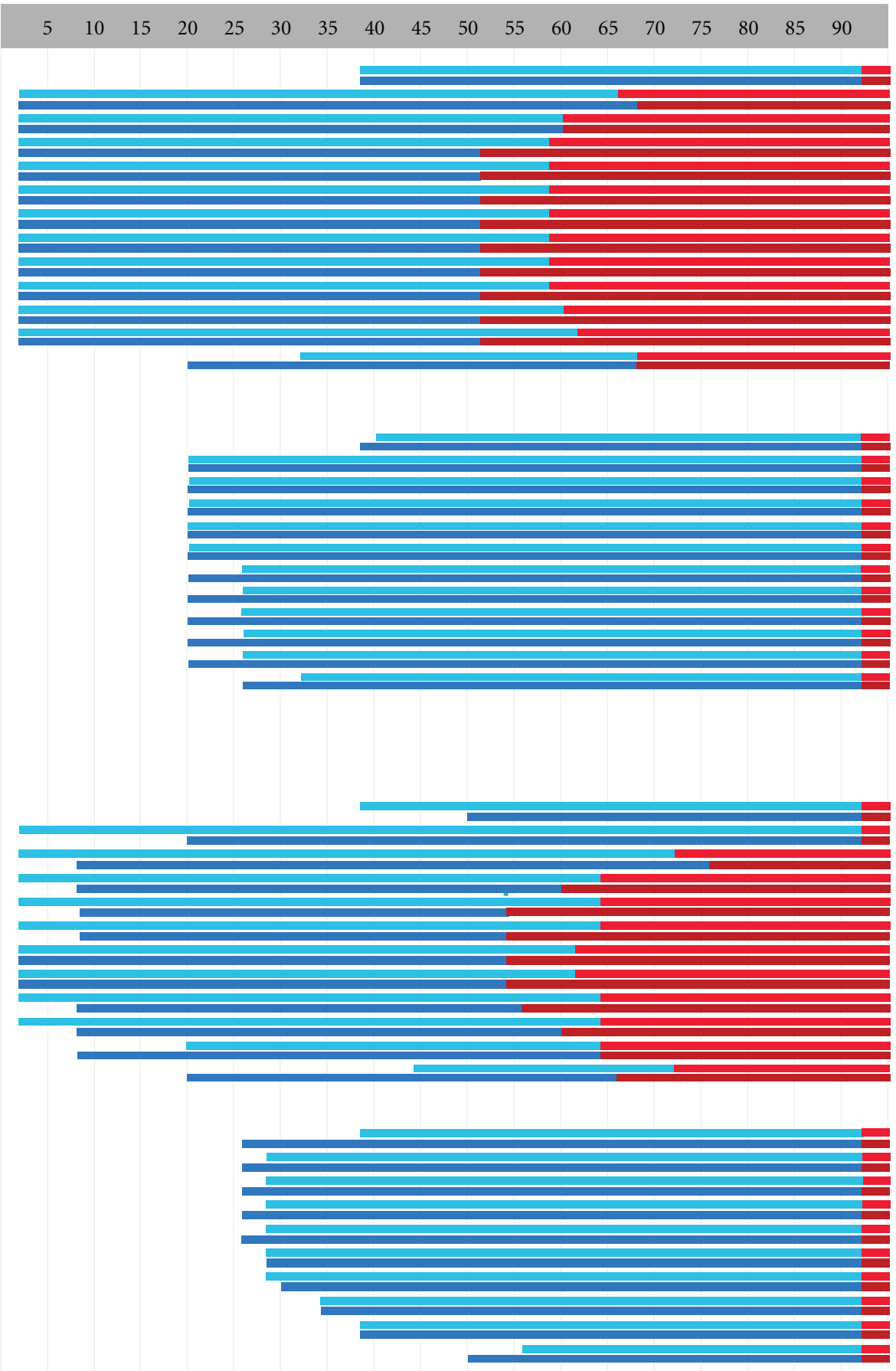

(2)

FIGURE 2: Sequence of chondrification and ossification for the elements of the dorsal and anal fins of Salvelinus alpinus reared in treatment $\mathrm{S}$ (slow; upper bars) and treatment F (fast; lower darker bars) between dph 2 and 90 . Blue is for cartilage, and red is for bone.

ossified elements). Independently of the three median fins, the timing of chondrification for c. $46 \%$ of the elements remains unchanged in both treatments whereas c. 64\% of the elements ossify earlier in treatment F (Figures 2-4). Certain bones, such as neural spine 2, display a temporal shift of 16 days later in treatment $\mathrm{F}$ (this shift is even more pronounced for this element in chondrification, 24 days,
Figures 3 and 4). The sequence of chondrification $(n=65)$ and ossification $(n=44)$ combining all fins elements (only the elements for which a specific day of appearance is known) are fairly congruent between treatments (chondrification: $r_{s}=0.89522, P<.0001$; ossification: $r_{s}=0.92503, P<$ $.0001)$, revealing similar timing of first appearance of skeletal elements between treatments. 


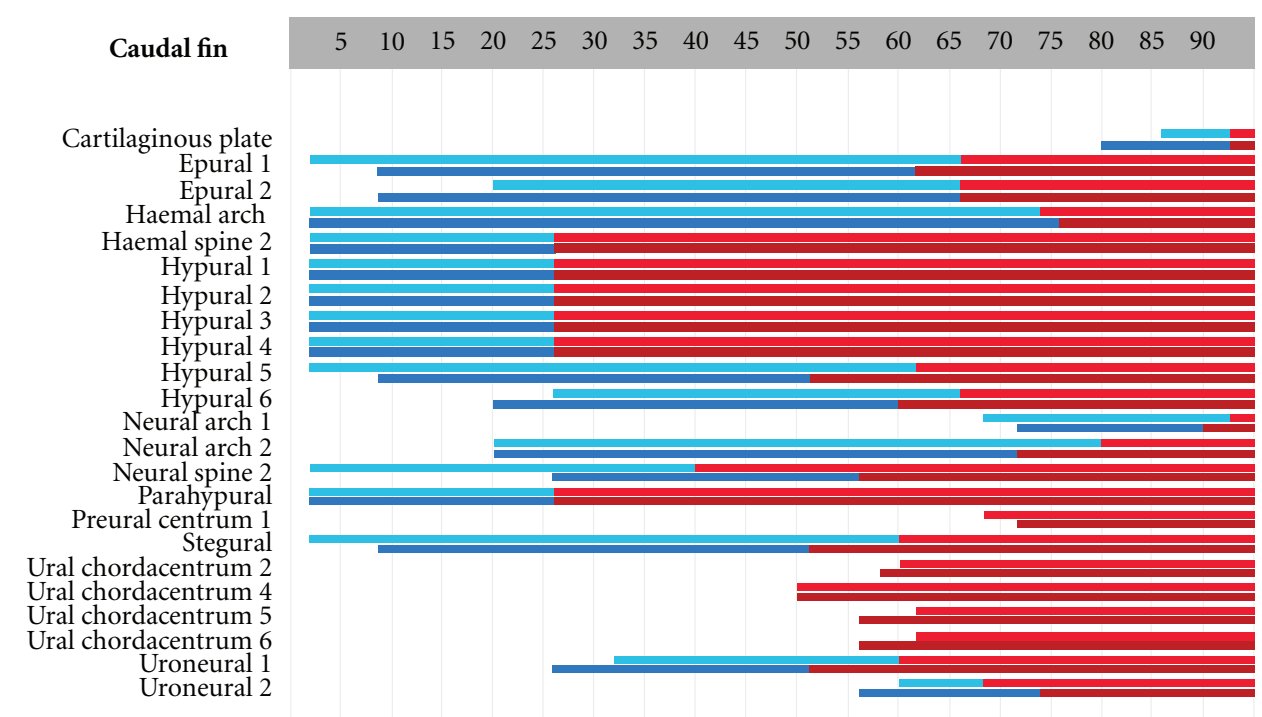

$\begin{array}{llllllllllllllllll}5 & 10 & 15 & 20 & 25 & 30 & 35 & 40 & 45 & 50 & 55 & 60 & 65 & 70 & 75 & 80 & 85 & 90\end{array}$

Figure 3: Sequence of chondrification and ossification for the elements of the caudal fin of Salvelinus alpinus reared in treatment S (slow, upper bars) and treatment $\mathrm{F}$ (fast; lower darker bars) between dph 2 and 90 . Blue is for cartilage, red is for bone.

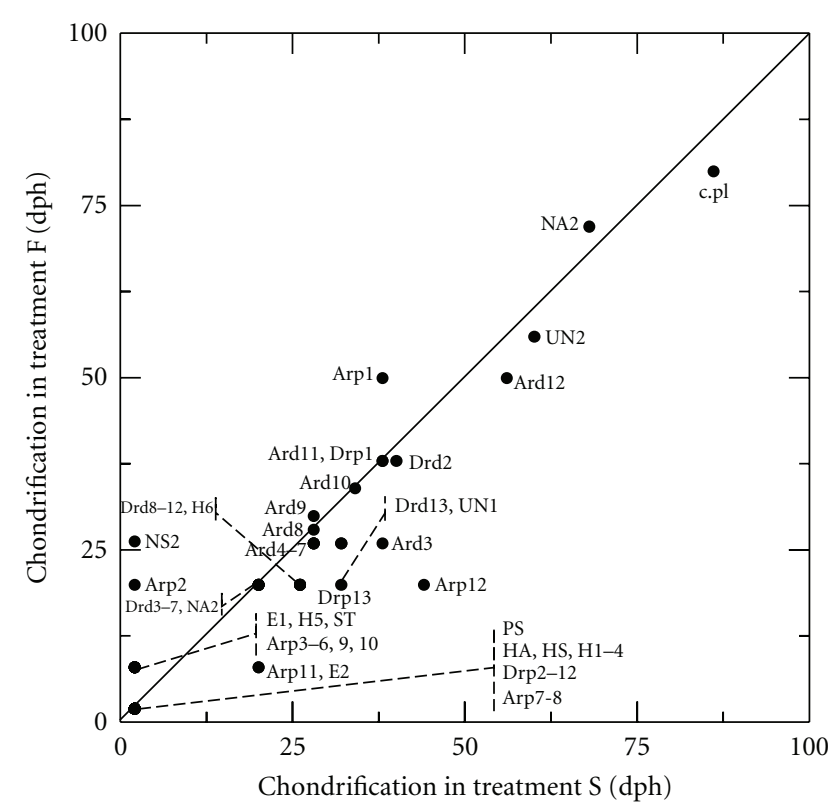

(a)

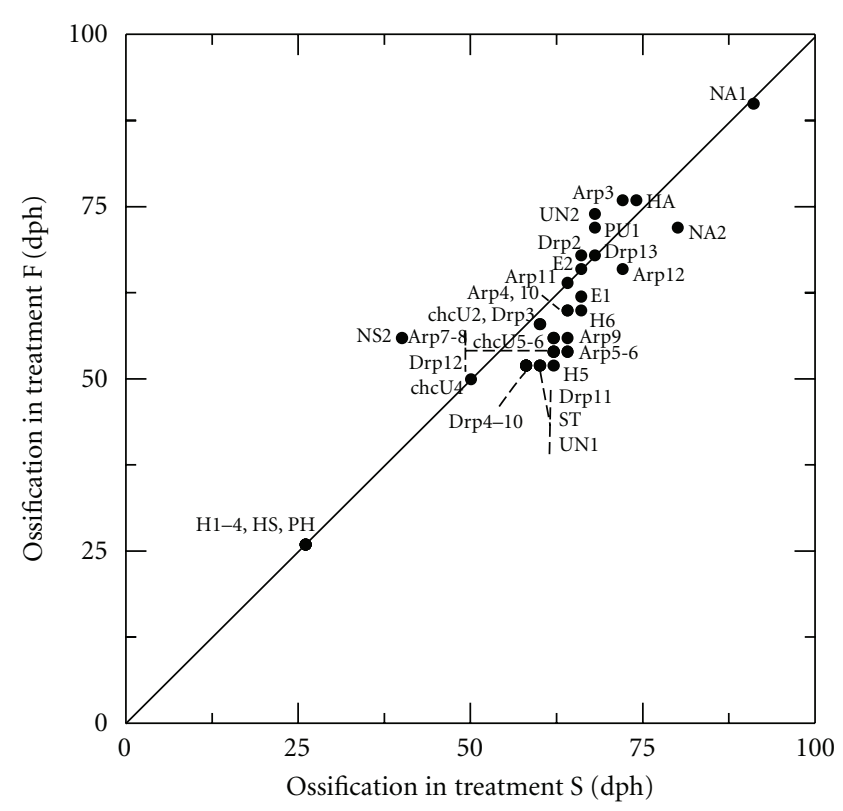

(b)

FIGURE 4: Biplots of the absolute timing of chondrification (a) and ossification (b) for all postcranial elements studied in Salvelinus alpinus between day 2 and 90. The synchrony line corresponds to a simultaneous appearance of elements in both treatments. Elements figuring above the line are those forming in Treatment $\mathrm{S}$ before Treatment $\mathrm{F}$, whereas the elements below the line form earlier in Treatment $\mathrm{F}$ than in Treatment S.

On average, the cartilaginous elements of the caudal and anal fins form approximately at the same time with respect to both treatments $(0.67$ day and 0.27 day later in treatment F; Table 1), whereas dorsal fin elements appear on average 2.00 days earlier in treatment F. Although not significant, there is a weak tendency for the chondrification of the caudal and anal fins to be slower in treatment F (Table 1).
The treatment effect is highly significant for the chondrification of the dorsal fin (Table 1). The chondrification of the caudal and anal fins displays greater variability than the dorsal fin whether it is expressed in terms of magnitude of difference inter-treatment or standard deviation (Table 1).

On average, caudal fin elements ossify 1.43 days earlier in treatment $\mathrm{F}$; this difference is not significant 


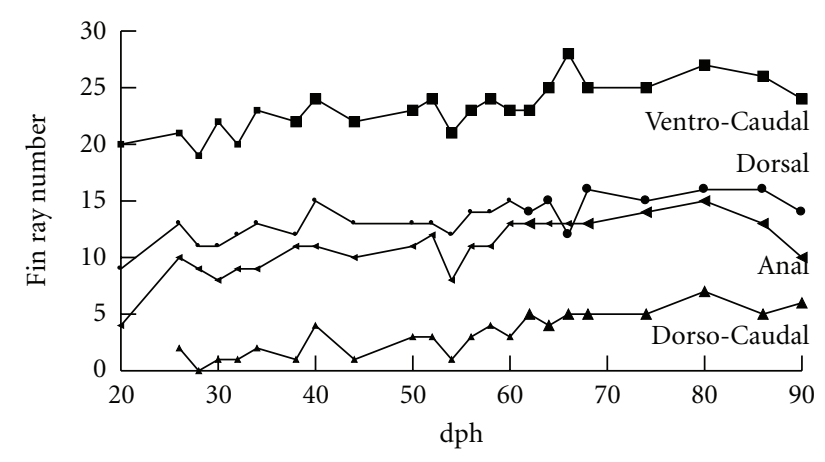

(a)

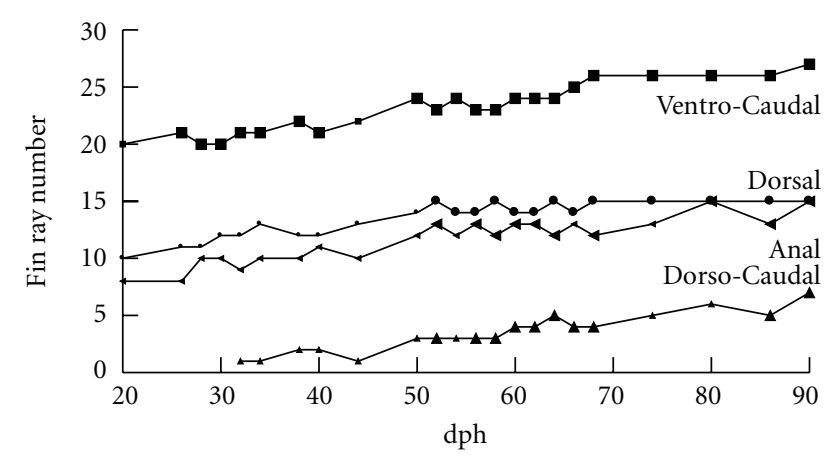

(b)

Figure 5: Formation of the fin rays for the three median fins of Salvelinus alpinus in Treatment S (a) and F (b) between day 20 and 90. Small and large symbols correspond to the presence of the cartilaginous actinotrichia and the ossification of the lepidotrichia, respectively.

TABle 1: Descriptive statistics for difference in the first appearance of cartilaginous and ossified elements (dph in treatment $\mathrm{S}-\mathrm{dph}$ in treatment F) for the three median fins of Salvelinus alpinus reared under two treatments of water velocity (treatments S and F). Positive differences indicate that elements are forming earlier in the faster treatment, whereas negative differences indicate that elements are forming earlier in the slower treatment. $n$ is the number of coded elements for which the time of appearance was available for both treatments (less than 90 days). Min and max are the minimal and maximal difference in dph, respectively. Mean and SD describe the average difference. $P$ is the probability associated with a $t$-test comparing the mean with a theoretical value of zero (no treatment effect).

\begin{tabular}{|c|c|c|c|c|c|c|c|c|c|c|c|c|}
\hline & \multicolumn{6}{|c|}{ Chondrification } & \multicolumn{6}{|c|}{ Ossification } \\
\hline & $n$ & $\min$ & $\max$ & mean & SD & $P$ & $n$ & $\min$ & $\max$ & mean & SD & $P$ \\
\hline Caudal & 18 & -24 & 12 & -0.6667 & 7.514691 & .7113 & 21 & -16 & 10 & 1.4257 & 5.8700 & .2770 \\
\hline Anal & 22 & -18 & 24 & -0.2727 & 8.735161 & .8850 & 10 & -4 & 10 & 5.4000 & 4.5264 & .0044 \\
\hline Dorsal & 25 & 0 & 12 & 2.0000 & 3.316625 & .0060 & 12 & -2 & 8 & 4.8333 & 3.1286 & .0002 \\
\hline
\end{tabular}

(Figure 3; Table 1). In treatment F, the elements of the dorsal fin ossify on average 4.83 days earlier whereas for the anal fin they ossify on average 5.4 days earlier. The treatment effect is highly significant for the ossification of the anal and dorsal fins (Table 1).

Between day 20 and 90, the formation of each fin ray (lepidotrichium) includes two distinct phases (Figure 5): (1) the appearance of the fin rays support, the actinotrichia, that are composed of elastoidin fibers that are laid down by the ectoderm [68] and (2) the dermal ossification of the lepidotrichia. The number of fin rays for each fin increases slowly during the 90 days period. The number of fin rays per fin in treatment $S$ is more variable than in treatment F; however, the low sample size might have introduced this variation. The number of fin rays per fin does not differ between treatments; it is slightly higher than the meristic counts provided by Vladykov [67] for adult S. alpinus. The lepidotrichia of the ventral part of the caudal fin are the first to ossify in both treatments, followed by a simultaneous ossification of the lepidotrichia in the dorsal and anal fins as well as the dorso-caudal lepidotrichia. The lepidotrichia ossify earlier in treatment $\mathrm{F}$ than in treatment S: 12 days earlier for the ventro-caudal rays and 10 days earlier for the dorsal and anal fins as well as the dorso-caudal rays.

3.4. Relative Timing within Morphological Systems. In the following section, the effect of treatment is evaluated in terms of magnitude of rank shift for element formation or ossification (i.e., relative order of event) rather than the difference in terms of the number of days. Rank shifts and associated statistics are represented for the chondrification and ossification of the three fins in Figure 6. Out of 65 elements, 27 elements (41.5\%) show an acceleration of chondrification in the treatment S, 15 elements $(23.1 \%)$ do not change their rank in the sequence, and 23 elements $(35.4 \%)$ show acceleration in treatment $\mathrm{F}$. With respect to the ossification of the 44 elements, 20 elements (45.4\%) show an acceleration of ossification in treatment $\mathrm{S}$, eight elements (18.2\%) do not change their rank between treatments, and 16 elements (36.4\%) show an acceleration of ossification in treatment F. Globally, the relative proportions of rank shift are similar during chondrification and ossification. In contrast to the absolute changes, more changes occur earlier in treatment $\mathrm{S}$ than treatment $\mathrm{F}$ in terms of rank shift.

During chondrification, the dorsal fin has the lowest variation of rank shift ( $\mathrm{SE}=0.4000)$. In terms of chondrification, $22 \%$ of the 18 caudal elements form earlier in treatment $S$ than in treatment F. Neural spine 2 shows the greatest rank shifts in terms of both chondrification and ossification. For the dorsal fin, approximately half of the 25 elements do not change ranks between treatments; 14 elements display rank shifts with seven elements shifting ranks either to occur faster in favour of treatments $\mathrm{S}$ or $\mathrm{F}$. In the dorsal fin, Drp13 is the cartilaginous element displaying the greatest magnitude of rank shift (6) forming earlier in treatment F. The chondrification of the anal fin is characterized by 


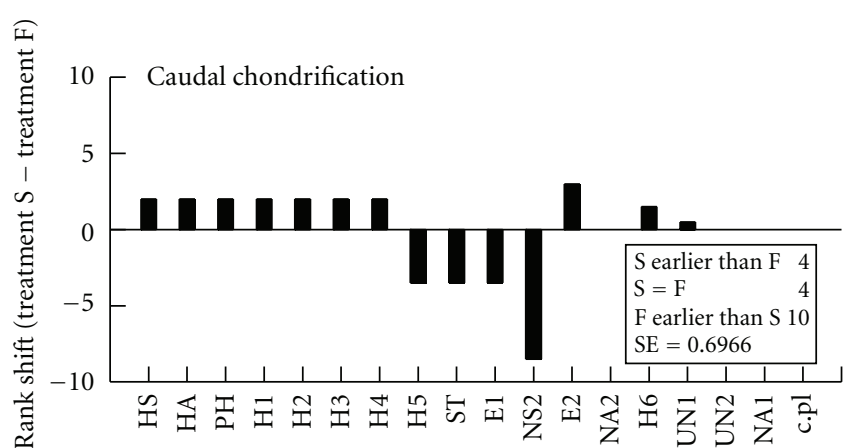

(a)

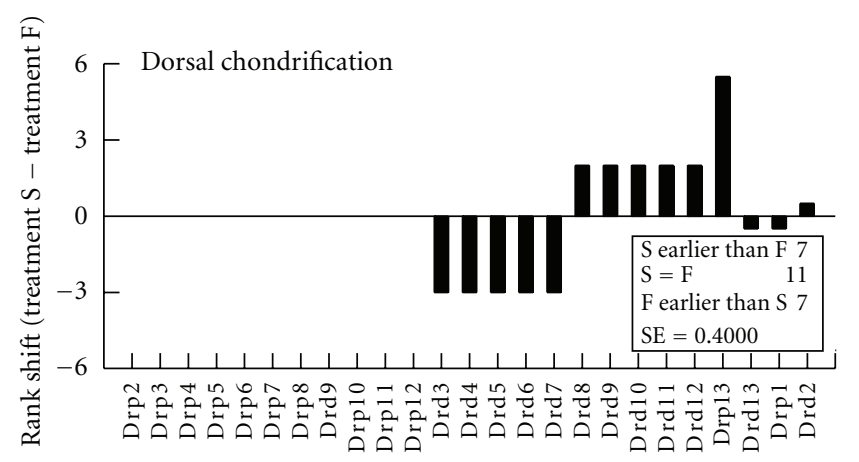

(c)

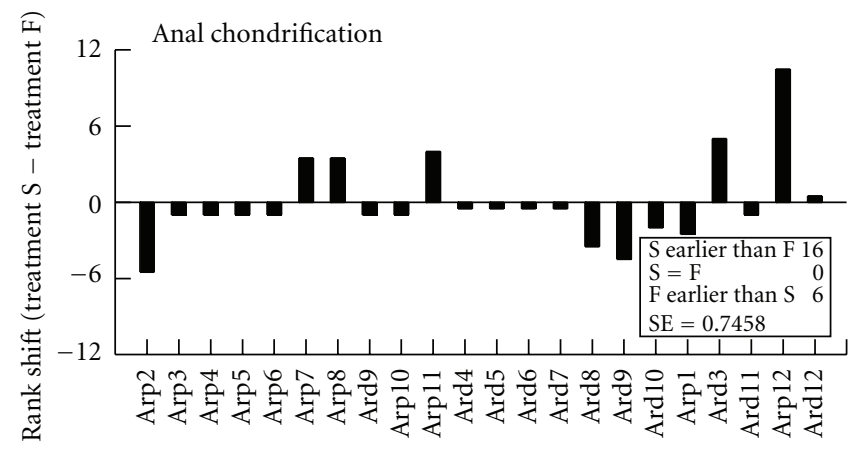

(e)

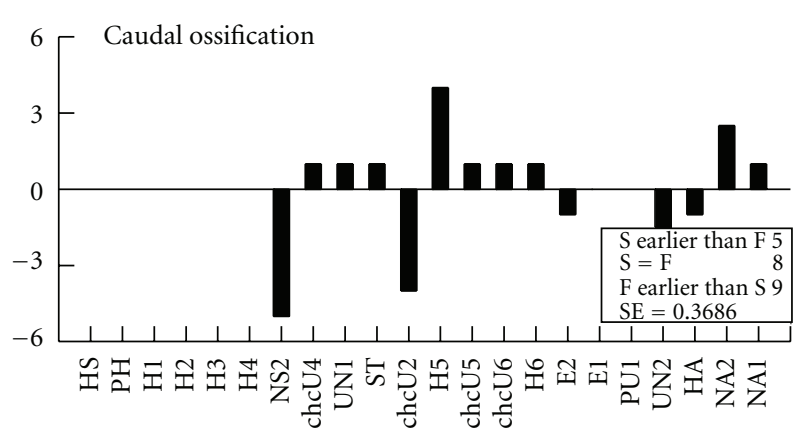

(b)

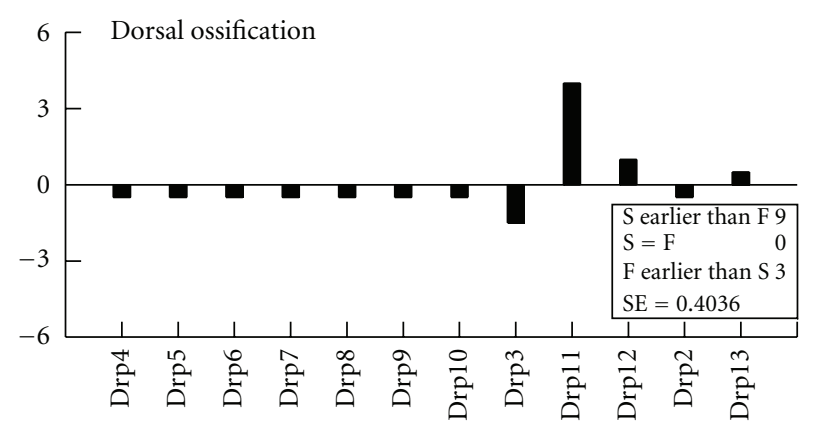

(d)

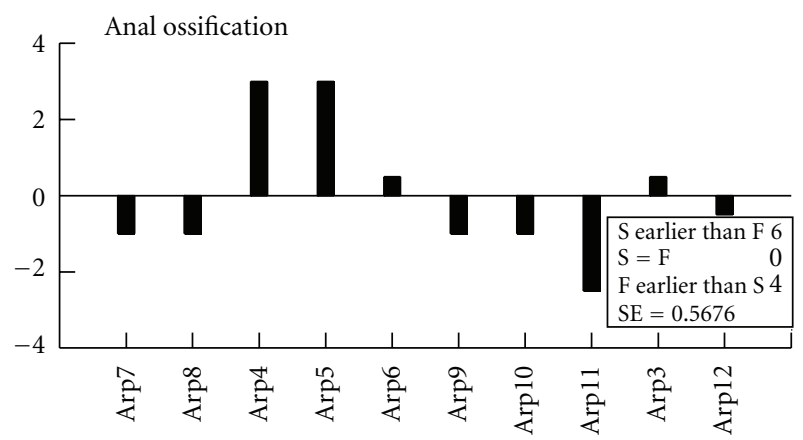

(f)

Figure 6: Histograms of magnitude of rank shifts for the chondrification (a, c, e) and ossification (b, d, f) of the three median fins [caudal $(\mathrm{a}, \mathrm{b})$, dorsal (c, d) and anal (e, f)] in Salvelinus alpinus. Rank shifts are calculated as the difference of rank from treatment $S$ to treatment $\mathrm{F}$. Elements are listed in the order of their appearance in treatment $\mathrm{S}$. Numbers of relative shifts and standard errors on the average rank shifts are provided for each histogram.

the greatest proportion of elements forming in treatment $S$ before treatment $\mathrm{F}(73 \%)$, the greatest magnitude (10.5 ranks for Arp12), and the greatest variation $(\mathrm{SE}=0.7458)$. For the dorsal and anal fins, the greatest magnitudes are associated with some of the last elements to chondrify in their respective fins and they are located at the posterior anatomical limit of these fins.

During ossification, the caudal fin has the lowest variation of rank shift ( $\mathrm{SE}=0.3686)$. Approximately $36 \%$ of the caudal elements (8) occupied the same rank in both treatments. Nine elements shifted earlier in the sequence in treatment $\mathrm{F}$ whereas five shifted later. Most elements of the dorsal fin show very low rank shift with the exception of Drp11. However, $75 \%$ of the elements ossify earlier in treatment $S$; this high proportion is associated with the relative importance of rank shift for Drp11. In contrast to the chondrification, proportions of rank shift are similar for the ossification of the anal and dorsal fins.

The general patterns of chondrification and ossification are congruent between treatments as can be validated by the Spearman rank correlation coefficients (Table 2). Coefficients (chondrification in treatment $\mathrm{S}$ versus chondrification in treatment $\mathrm{F}$, and ossification in treatment $\mathrm{S}$ versus ossification in treatment F) are highly significant, meaning that the patterns are congruent independently of the treatment. Most correlations between chondrification and ossification of different treatments are also significant but with lower rank correlation and lower level of significance; non-significant 
patterns observed for the anal and dorsal fins might be a result of the low number of ossified elements compared ( $n=$ 10 (anal) and 12 (dorsal)). The pattern of relative timing is more conservative in the caudal fin. The relative timing of ossification among the bones within each one of the fins is fairly consistent in the two treatments. Faster water velocity has induced minor inversions of events in the sequences for each fin (e.g., anterior and posterior proximal radials of the dorsal and anal fins). However, such inversions do not affect radically the cohesion of the developmental sequence of skeletogenesis.

3.5. Direction of Chondrification and Ossification. In the caudal fin, directions are provided for the two epurals, two uroneurals, six hypurals, and the four ural chordocentra whereas numerous proximal and distal radials are used for the dorsal and anal fins (Table 3 ). With respect to the seven elements for which direction of chondrification is available, two of them have the potential to have been affected by the treatment whereas only one out of eight has been clearly affected with regard to the ossification (Table 3 ).

In the caudal fin, the chondrification and ossification of the epurals, uroneurals and hypurals in both treatments proceed primarily from anterior to posterior. The minor shift in the timing of chondrification and ossification observed in epurals suggests that both epurals could form simultaneously; the simultaneity results from opposing effect of water velocity on the two forming epurals (see Figure 3 ) or the low number of elements from which a direction is determined. Because hypurals 1-4 form as a block very early in ontogeny (or separate prehatching stages not sampled for this study), directionality is provided by the development of hypurals 5 and 6 . The direction of ossification of the ural chordacentra is problematical owing to the sporadic presence of chondacentra 5 and 6 among the observed specimens. In both treatments, ural chordacentrum 4 ossifies before chordacentrum 2. This suggests a direction of formation from posterior to anterior. However, the ossification of ural chordacentra 5 and 6 precedes the formation of ural chordacentrum 2 in treatment $\mathrm{F}$ whereas it is formed after ural chordacentrum 2 in treatment S. Thus, a bidirectional formation is observed in both treatments with a variation in the alternation of the relative order of ural chordacentra 2 and 5-6 with reference to ural chordacentrum 4 .

Although most proximal radials of the dorsal fin are present at $2 \mathrm{dph}$, chondrification proceeds bidirectionally as indicated by the late appearance of proximal radials 1 and 13 (Figure 2). In both treatments, the ossification of the dorsal fin is bidirectional. This bidirectionality is clearer in treatment $S$ whereas a slight tendency to shift posteriorly is observed in treatment F. A bidirectional formation for the distal radials of the dorsal fin is interpreted solely because of the chondrification of distal radial 2; however, the general tendency is from anterior to posterior. The direction of ossification for the distal radials remains unknown because they were still cartilaginous at $90 \mathrm{dph}$ in both treatments.

The proximal radials of the anal fin show indication of bidirectional chondrification in treatment $S$ although only proximal radial 1 suggests an anterior component to the bidirectionality. However, in treatment $\mathrm{F}$, the chondrification of the proximal radials of the anal fin is clearly bidirectional. In contrast to the proximal radials, chondrification of the distal radials of the anal fin proceeds clearly from anterior to posterior in treatment $\mathrm{F}$; however, in treatment $\mathrm{S}$, the formation of distal radial 3 suggests a bidirectional formation (Figure 2).

In both the dorsal and anal fins, proximal radials form before the distal radials; thus a proximo-distal direction of chondrification and ossification is similar in both fins.

Directions of chondrification and ossification among serially repeated elements for the median fins are highly conservative. In general, the formation of the different caudal elements proceeds from anterior to posterior. The development of the dorsal and anal fins (Table 3) proceeds (1) from proximal to distal within each fin and (2) primarily bidirectionally for the radials. However, there might be a tendency to shift from a bidirectional pattern towards an antero-posterior pattern in the formation of the dorsal and anal fins. With the exception of the epurals in the caudal fin and the distal radials of the anal fin, the treatment has no effect on the direction of chondrification and ossification.

\section{Discussion}

4.1. Developmental Plasticity. The morphology of salmonids is known to be plastic. Numerous studies [51-59, 69] have demonstrated the effect of water velocity on body size and shape for different species of salmonids. None of these studies addressed the potential effect of water velocity on the skeletal anatomy of these fishes. However, Fischer-Rousseau et al. [36], in comparing the development of brook charrs Salvelinus fontinalis captured in stream and lake, not only demonstrated differences in shape, level of integration, and structure of variation between the habitats but also observed that ossification events (for the complete postcranial skeleton) in stream fishes occur at a significantly smaller size. It was suggested that a muscular functional demand was potentially responsible for this difference in ossification timing. In the present study, we show experimentally for the first time the effect of water velocity on the timing of first appearance, and to a lesser extent on the relative timing of appearance and the direction of chondrification and ossification. Water velocity has a differential effect on the absolute timing of chondrification versus ossification, as well as on the different median fins. However, the observed timing changes have only a low impact on the order of events within the sequences themselves.

Developmental plasticity on the timing and rate of development in fishes has already been suggested. Sfakianakis et al. [70] reported the absence of temperature effect on the pattern of osteological development of the postcranial skeleton of the common pandora Pagellus erythrinus but demonstrated an effect on the rate of development. Fuiman et al. [71] mentioned that temperature might accelerate the rate of development more than the growth rate. In the present study, similar patterns have been found for $S$. alpinus although water velocity rather than temperature was tested. The treatment had no significant effect on growth although 
TABLE 2: Spearman rank correlation for the three median fins of Salvelinus alpinus reared under two treatments of water velocity (treatments $\mathrm{S}$ and F). $n$ is the number of coded elements for which the time of appearance was available for both treatments (less than 90 days). $P$ is the probability associated with a $r_{\mathrm{s}}$.

\begin{tabular}{|c|c|c|c|c|c|c|c|}
\hline & \multirow[b]{3}{*}{ Treatment S } & \multicolumn{6}{|c|}{ Treatment F } \\
\hline & & \multicolumn{2}{|c|}{ Caudal } & \multicolumn{2}{|c|}{ Dorsal } & \multicolumn{2}{|c|}{ Anal } \\
\hline & & Chondrification & Ossification & Chondrification & Ossification & Chondrification & Ossification \\
\hline \multirow{4}{*}{ Caudal } & Chondrification & 0.82344 & 0.62800 & & & & \\
\hline & & $\begin{array}{l}(n=18 \\
P<.0001)\end{array}$ & $\begin{array}{l}(n=17 \\
P=.0069)\end{array}$ & & & & \\
\hline & Ossification & 0.60878 & 0.95739 & & & & \\
\hline & & $\begin{array}{l}(n=16 \\
P=.0123)\end{array}$ & $\begin{array}{l}(n=22 ; \\
P<.0001)\end{array}$ & & & & \\
\hline \multirow{4}{*}{ Dorsal } & Chondrification & & & 0.95808 & 0.52093 & & \\
\hline & & & & $\begin{array}{l}(n=25 \\
P<.0001)\end{array}$ & $\begin{array}{l}(n=12 ; \\
P=.0825)\end{array}$ & & \\
\hline & Ossification & & & 0.53685 & 0.90191 & & \\
\hline & & & & $\begin{array}{l}(n=12 ; \\
P=.0719)\end{array}$ & $\begin{array}{l}(n=12 ; \\
P<.0001)\end{array}$ & & \\
\hline \multirow{4}{*}{ Anal } & Chondrification & & & & & 0.84468 & 0.54617 \\
\hline & & & & & & $\begin{array}{l}(n=22 ; \\
P<.0001)\end{array}$ & $\begin{array}{l}(n=10 \\
P=.1024)\end{array}$ \\
\hline & Ossification & & & & & 0.88454 & 0.79772 \\
\hline & & & & & & $\begin{array}{l}(n=10 \\
P=.0007)\end{array}$ & $\begin{array}{l}(n=10 \\
P=.0057)\end{array}$ \\
\hline
\end{tabular}

TABle 3: Direction of chondrification and ossification for the serially repeated elements of the median fins of Salvelinus alpinus reared under two treatments of water velocity (treatments $S$ and F). Three conditions of direction have been interpreted: antero-posterior (A to $\mathrm{P}$ ), bidirectional, and simultaneous (all elements forming simultaneously). (?) refers to ambiguous directionality (see text). NA is for not applicable. Bold-face indicates difference between treatments.

\begin{tabular}{|c|c|c|c|c|}
\hline & \multicolumn{2}{|c|}{ Chondrification } & \multicolumn{2}{|c|}{ Ossification } \\
\hline & Treatment S & Treatment F & Treatment S & Treatment F \\
\hline \multicolumn{5}{|l|}{ Caudal fin } \\
\hline Epurals & A to $P$ & simultaneous & simultaneous & A to $P$ \\
\hline Uroneurals & A to $P$ & A to $\mathrm{P}$ & A to $\mathrm{P}$ & A to $\mathrm{P}$ \\
\hline Hypurals & A to $P$ & A to $P$ & A to $\mathrm{P}$ & A to $\mathrm{P}$ \\
\hline Ural chordocentra & NA & NA & bidirectional & bidirectional \\
\hline \multicolumn{5}{|l|}{ Dorsal fin } \\
\hline Proximal radials & bidirectional & bidirectional & bidirectional & bidirectional (?) \\
\hline Distal radials & bidirectional (?) & bidirectional & NA & NA \\
\hline \multicolumn{5}{|l|}{ Anal fin } \\
\hline Proximal radials & bidirectional (?) & bidirectional & bidirectional & bidirectional \\
\hline Distal radials & bidirectional (?) & A to $P$ & NA & NA \\
\hline
\end{tabular}

significant changes in the absolute timing were found where elements ossify earlier in the higher velocity treatment. The absence of effect on growth during the 90-day period is most likely owing to the weak difference of water velocity between our two treatments; significant differences in growth rate of $S$. alpinus were found associated with greater differential water velocities [58].

Certain environmental or experimental constraints induce differential mechanical stress and loading by muscular forces, which may involve plastic response of an organism or more specifically of its bones [72-75]. Such mechanical stress may originate from functional and behavioural needs [35, 41, 76-78]. Rearing fishes in different water velocities most likely affected their locomotion and therefore the mechanical stress exerted on the musculoskeletal system. Different lines of evidence have demonstrated the correlative link between muscles and cartilages-bones ((1) induced paralysis in developing chick embryo [79, 80], (2) comparison between normal and muscleless mouse embryo mutants $[74,81]$, and (3) osteological comparison in asymmetrical 
training in humans $[82,83])$. Responses correlated to higher muscular stress or activities include increases in numerous structural parameters (total bone volume, bone mineral density, bone mineral content, bone mass, and osteon density $[74,75,78-86])$. In addition to these structural differences, Hosseini and Hogg [79] observed a delay in the timing of first appearance for the ossification for 15 elements in the paralyzed chick embryo. Furthermore, earlier ossifying bones were less affected than later developing bones [79].

Overall, the ossification of fin supports and fin rays is faster in the higher water velocity, and the responses are more important in the dorsal and anal fins whereas the pattern is globally more conservative for the caudal fin. Although the formation of the ventral elements of the caudal fin (haemal spine 2, parhypural, and hypurals 1-4) is similar in both treatments, the sequences of chondrification and ossification of the dorsal elements differ. The absolute timing of epural 1, uroneural 1 and neural arch 2 display a greater plasticity than the parhypural and hypurals $1-4$. These dorsal structures of the caudal fin are located in proximity of the stegural, where mechanical stresses are important due to the thrust propagation along the posterior part of the notochord [87]. Most of the mechanical stresses associated with the subcarangiform locomotion might be taken by the stegural that strengthens the caudal fin. Given that skeletogenesis and to a greater extent ossification are sensitive to environmental inductions and mechanical stimulations [41], the timing of dorsal elements might be more plastic. Changes in timing of ossification of certain elements provide adaptive responses of skeletal systems involved in functional needs $[35,75,87]$.

Most of the elements forming the skeleton of the median fins are cartilage bones, either endochondral or perichondral, with the exception of the ural chordacentra associated with the caudal fin that do not have cartilaginous precursors. Differential responses between chondrification and ossification to an experimental treatment have already been reported in fishes. Mabee et al. [35] noted differential responses to temperature treatment between cranial cartilage bones and dermal bones. In zebrafish, cartilage and dermal bones did not differ in their average timing of development among temperatures, but cartilage bones were more variable than dermal bones [35]. Campinho et al. [48] reported the ossification to be more sensitive than chondrification to a temperature treatment. A difference in velocity, as minimal as the one tested experimentally in the present study, has an effect on the timing of the ossification events and to a lesser extent on the chondrification events. Since the effects differ in the two sets of developmental events, we can assume that the pattern of ossification is partially independent from the pattern of chondrification. Partial independence between these sequences has already been shown with regards to the development of the caudal fin of some catostomids [7]. Most of the chondrification of the median fins of S. alpinus is completed during the first 50 days of the experiment whereas most of the ossification is not initiated before day 50 . Because of the duration of exposure to the experimental constraint, it is suggested that the chondrification pattern is more under genetic control with a minimal epigenetic component whereas the ossification pattern, although also controlled genetically, might have a greater epigenetic component than the chondrification pattern. Evidently, the process of endochondral bone formation is strongly dependent of the coordination between chondrocyte and osteoblast differentiation associated with a cascade of several factors at the molecular and cellular levels [88]. However, skeletogenesis might be regulated by epigenetic effects such as mechanical stimulation and environmental modifications $[41,74,85]$. Thus, one may argue that because of the potential epigenetic effect of environmental modifications on skeletal structure development, the cartilaginous-bony dependence at the molecular level is not necessarily a warranty of a complete dependence of cartilages and bones at the structural level.

Magnitude rank shift is very low in average for each fin, the majority of elements shifting only from one or two ranks. This low variability is responsible for the highly conservative sequence of events whether comparing chondrification sequences or ossification sequences. Such low level of variability had been reported for the cranial elements of Danio rerio and Betta splendens reared at different temperatures [35]. Our results suggest that median fin structures are relatively well integrated given the conservative sequence and the low level of variability.

4.2. Anatomical Variation. We provided the first description of the chondrification and ossification sequences for the median fins of Salvelinus alpinus. This description completes previous descriptions of the median fin supports of $S$. alpinus $[33,44,67]$. The characterization of this developmental sequence also provided the opportunity to report anatomical variation among the components of the median fins.

In addition to the plasticity in the timing and the position of events in the sequence, certain elements display a greater level of anatomical variation. Although we have only qualified these anatomical variations, they are worth mentioning and interpreting; further studies would have to quantify this variation and test the effect of the water velocity treatment on the pattern of variation. The greatest variation in terms of anomalies (e.g., fusion, additional elements) and magnitude of rank-shift is present in the most anterior and most posterior proximal and distal radials of the dorsal and anal fins; these elements correspond to the peripheral serially repeated elements of these series. Two hypotheses are suggested to explain the topographic position of this variation. First, the variability could be the result of suboptimal experimental conditions [46, 89]; however, rearing conditions were selected to be acceptable or optimal for S. alpinus [58, 62]. Significantly higher occurrence of skeletal malformations of the vertebral column were reported in sea bass Dicentrarchus labrax [90] and red sea bream Pagrus major [91] as a result of a higher water velocity. None of the anatomical variation observed in the dorsal and anal fins of $S$. alpinus have been identified in the sea bass and the red sea bream. Thus, the median fin variation of $S$. alpinus does not seem to be related to suboptimal rearing condition or the water velocity treatment. We are suggesting a second hypothesis in which the source of variation might be in 
relation to the peripheral topographic position of serially repeated elements at the edge of the fins. In a bidirectional mode of formation (such as the proximal radials of the dorsal and anal fins), peripheral serially repeated elements are the latest elements to appear in the sequence. One might expect that developmental constraints, such as integration or canalization, might be relaxed in peripheral serially repeated elements, and thus epigenetic constraints be more influential.

4.3. Modularity. Phenotypic developmental modules in fishes have been suggested based on direction of ossification. Mabee et al. [92] have identified various fin patterning as well as one positioning module and three patterning modules with respect to the median fins of actinopterygians. In the present study, we can only address two of the three patterning modules. Faustino and Power [93] and Mabee et al. [92] mentioned that the overall pattern of development of the dorsal and anal fin supports in teleosts is similar with a few exceptions. The dorsal and anal fins are characterized by a patterning module in which the skeletal elements of both fins differentiate bidirectionally. In S. alpinus, the proximal radials of the anal and dorsal fins form and ossify bidirectionally whereas no clear pattern was identified for the distal radials of both fins. Similar patterns of chondrification and ossification for these two fins have been described for sea bream Sparus aurata [93] and brook charr Salvelinus fontinalis [36]. Not only the patterns of formation are similar, but the initiation of ossification for both fins is similar in both treatments, the absolute timing is similar, and the response in terms of rank shift is also similar. Our results document for the first time the presence of the dorsal-anal fin patterning module in the Salmoniformes.

The second patterning module concerns the relation between exo- and endoskeleton in the development of all median fins [92]. In the dorsal and anal fins of S. alpinus, the proximal radials are the first structures to develop as cartilages, followed by the distal radials and their respective fin rays. The formation of the lepidotrichia requires the presence of the radials but not their ossification. Similar sequences have been reported previously for different teleosts [92-95]. The conservation of this patterning is expected since an induction mechanism has been shown between the radial and the corresponding fin rays in the bastard halibut, Paralichthys olivaceus [96].

Patterning modules have been investigated using developmental sequences at the species level without consideration of environmental constraints. In the present study, we showed that an experimental constraint, namely the water velocity, has the potential to modify direction of both chondrification and ossification. Thus, one has to be aware that one of the defining criteria of patterning modules could be plastic. However, the plastic response has a tendency to be coordinated between modular components. On the other hand, this coordination of phenotypic plastic response could be used to test the robustness of developmental patterning modules. In further studies, it would be worth testing the cohesion and variation within modules on larger sample size as well as on a wider range of water velocity.

\section{Abbreviations}

$\begin{array}{ll}\text { Ard 3-12: } & \text { Anal distal radials 3-12 } \\ \text { Arp 1-12: } & \text { Anal proximal radials 1-12 } \\ \text { chcU2, 4-6: } & \text { Ural chordacentra 2, 4-6 } \\ \text { c.pl: } & \text { Cartilaginous plate } \\ \text { Drd 2-13: } & \text { Dorsal distal radials 2-13 } \\ \text { Drp 1-13: } & \text { Dorsal proximal radials 1-13 } \\ \text { E1-2: } & \text { Epural 1-2 } \\ \text { H1-H6: } & \text { Hypural 1-6 } \\ \text { HA: } & \text { Haemal arch } \\ \text { HS: } & \text { Haemal spine } \\ \text { HS2: } & \text { Haemal spine 2 } \\ \text { NA1-2: } & \text { Neural arches 1-2 } \\ \text { nc: } & \text { Notochord } \\ \text { NS2: } & \text { Neural spine 2 } \\ \text { PH: } & \text { Parhypural } \\ \text { PU1: } & \text { Preural centrum 1 } \\ \text { ST: } & \text { Stegural } \\ \text { UN1-2: } & \text { Uroneural 1-2. } \\ & \end{array}$

\section{Acknowledgments}

The authors specially thank M. Bélanger and V. Canévet (UQAR) for providing substantial assistance with the clearing and staining of the specimens. They thank B. Archer who was responsible for the fish rearing and the Centre Aquacole Marin de Grande-Rivière (Québec, Canada) for providing facilities during the experiment. They thank G. Arratia, K. Chu, L. Fischer-Rousseau, and B. Vincent for stimulating discussions. This research was supported by Natural Sciences and Engineering Research Council of Canada operating grant 238612 to the first author. Additional support was granted by a FIR from the Universite du Québec à Rimouski to R. Cloutier and N. R. Le François.

\section{References}

[1] S. E. Sultan, "Commentary: the promise of ecological developmental biology," Journal of Experimental Zoology, Part B, vol. 296, no. 1, pp. 1-7, 2003.

[2] S. F. Gilbert, "Ecological developmental biology: developmental biology meets the real world," Developmental Biology, vol. 233, no. 1, pp. 1-12, 2001.

[3] C. C. Cubbage and P. M. Mabee, "Development of the cranium and paired fins in the zebrafish Danio rerio (Ostariophysi, Cyprinidae)," Journal of Morphology, vol. 229, no. 2, pp. 121160, 1996.

[4] D. Adriaens and W. Verraes, "Ontogeny of the osteocranium in the African catfish, Clarias gariepinus Burchell (1822) (Siluriformes: Clariidae): ossification sequence as a response to functional demands," Journal of Morphology, vol. 235, no. 3, pp. 183-237, 1998.

[5] M. Faustino and D. M. Power, "Osteologic development of the viscerocranial skeleton in sea bream: alternative ossification strategies in teleost fish," Journal of Fish Biology, vol. 58, no. 2, pp. 537-572, 2001.

[6] N. C. Bird and P. M. Mabee, "Developmental morphology of the axial skeleton of the zebrafish, Danio rerio (Ostariophysi: Cyprinidae)," Developmental Dynamics, vol. 228, no. 3, pp. 337-357, 2003. 
[7] T. Grünbaum, R. Cloutier, and P. Dumont, "Congruence between chondrification and ossification sequences during caudal skeleton development: a Moxostomatini case study," in The Big Fish Bang, H. I. Browman and A. B. Skiftesvik, Eds., pp. 161-176, LFC/Institute of Marine Research, Bergen, Norway, 2003.

[8] R. E. Strauss, "Heterochronic variation in the developmental timing of cranial ossifications in poeciliid fishes (Cyprinodontiformes)," Evolution, vol. 44, pp. 1558-1567, 1990.

[9] R. Britz and K. W. Conway, "Osteology of Paedocypris, a miniature and highly developmentally truncated fish (Teleostei: Ostariophysi: Cyprinidae)," Journal of Morphology, vol. 270, no. 4, pp. 389-412, 2009.

[10] J. M. Engeman, N. Aspinwall, and P. M. Mabee, "Development of the pharyngeal arch skeleton in Catostomus commersonii (Teleostei: Cypriniformes)," Journal of Morphology, vol. 270, no. 3, pp. 291-305, 2009.

[11] A. Burdi and T. Grande, "Morphological development of the axial skeletons of Esox lucius and Esox masquinongy (Euteleostei: Esociformes), with comparisons in developmental and mineralization rates," in Origin and Phylogenetic Interrelationships of Teleosts, J. S. Nelson et al., Ed., pp. 411430, Dr. Friedrich Pfeil, München, Germany, 2010.

[12] R. Britz and G. D. Johnson, "Occipito-vertebral fusion in actinopterygians: conjecture, myth and reality. Part 1: nonteleosts," in Origin and Phylogenetic Interrelationships of Teleosts, J. S. Nelson et al., Ed., pp. 77-93, Dr. Friedrich Pfeil, München, Germany, 2010.

[13] G. D. Johnson and R. Britz, "Occipita-vertebral fusion in actinopterygians: conjecture, myth and reality. Part 2: teleosts," in Origin and Phylogenetic Interrelationships of Teleosts, J. S. Nelson et al., Ed., pp. 95-110, Dr. Friedrich Pfeil, München, Germany, 2010.

[14] C. A. Boisvert, "Vertebral development of modern salamanders provides insights into a unique event of their evolutionary history," Journal of Experimental Zoology, Part B, vol. 312, no. 1, pp. 1-29, 2009.

[15] C. A. Sheil and H. Alamillo, "Osteology and skeletal development of Phyllomedusa vaillanti (Anura: Hylidae: Phyllomedusinae) and a comparison of this arboreal species with a terrestrial member of the genus," Journal of Morphology, vol. 265, no. 3, pp. 343-368, 2005.

[16] L. Trueb, L. A. Púgener, and A. M. Maglia, "Ontogeny of the bizarre: an osteological description of Pipa pipa (Anura: Pipidae), with an account of skeletal development in the species," Journal of Morphology, vol. 243, no. 1, pp. 75-104, 2000.

[17] J. Hanken and B. K. Hall, "Variation and timing of the cranial ossification sequence of the oriental fire-bellied toad, Bombina orientalis (Amphibia, Discoglossidae)," Journal of Morphology, vol. 182, no. 3, pp. 245-255, 1984.

[18] L. Trueb, "A summary of osteocranial development in anurans with notes on the sequence of cranial ossification in Rhinophrynus dorsalis (Anura: Pipoidea: Rhinophrynidae)," South African Journal of Science, vol. 81, pp. 181-185, 1985.

[19] A. Haas, "Larval and metamorphic skeletal development in the fast-developing frog Pyxicephalus adspersus (Anura, Ranidae)," Zoomorphology, vol. 119, no. 1, pp. 23-35, 1999.

[20] I. Werneburg and M. R. Sánchez-Villagra, “Timing of organogenesis support basal position of turtles in the amniote tree of life," BMC Evolutionary Biology, vol. 9, no. 1, article no. 82, 2009.
[21] I. Werneburg, J. Hugi, J. Müller, and M. R. Sánchez-Villagra, "Embryogenesis and ossification of Emydura subglobosa (Testudines, Pleurodira, Chelidae) and patterns of turtle development," Developmental Dynamics, vol. 238, no. 11, pp. 27702786, 2009.

[22] C. A. Sheil, "Osteology and skeletal development of Apalone spinifera (Reptilia: Testudines: Trionychidae)," Journal of Morphology, vol. 256, no. 1, pp. 42-78, 2003.

[23] O. Rieppel, "Studies on skeleton formation in reptilespatterns of ossification in the skeleton of Lacerta agilis exigua Eichwald (Reptilia, Squamata)," Journal of Herpetology, vol. 28, pp. 145-153, 1994.

[24] O. Rieppel, "Studies on skeleton formation in reptiles. V. Patterns of ossification in the skeleton of Alligator mississippiensis Daudin (Reptilia, Crocodylia)," Zoological Journal of the Linnean Society, vol. 109, no. 3, pp. 301-325, 1993.

[25] D. A. Hogg, "A re-investigation of the centres of ossification in the avian skeleton at and after hatching," Journal of Anatomy, vol. 130, no. 4, pp. 725-743, 1980.

[26] E. E. Maxwell, "Ossification sequence of the avian order Anseriformes, with comparison to other precocial birds," Journal of Morphology, vol. 269, no. 9, pp. 1095-1113, 2008.

[27] E. E. Maxwell, "Comparative embryonic development of the skeleton of the domestic turkey (Meleagris gallopavo) and other galliform birds," Zoology, vol. 111, no. 3, pp. 242-257, 2008.

[28] E. E. Maxwell and L. B. Harrison, "Ossification sequence of the common tern (Sterna hirundo) and its implications for the interrelationships of the Lari (Aves, Charadriiformes)," Journal of Morphology, vol. 269, no. 9, pp. 1056-1072, 2008.

[29] M. R. Sánchez-Villagra, "Comparative patterns of postcranial ontogeny in therian mammals: an analysis of relative timing of ossification events," Journal of Experimental Zoology, Part B, vol. 294, no. 3, pp. 264-273, 2002.

[30] M. R. Sánchez-Villagra, A. Goswami, V. Weisbecker, O. Mock, and S. Kuratani, "Conserved relative timing of cranial ossification patterns in early mammalian evolution," Evolution and Development, vol. 10, no. 5, pp. 519-530, 2008.

[31] O. R. P. Bininda-Emonds, J. E. Jeffery, M. R. Sánchez-Villagra et al., "Forelimb-hindlimb developmental timing changes across tetrapod phylogeny," BMC Evolutionary Biology, vol. 7, article no. 182, 2007.

[32] V. Weisbecker, A. Goswami, S. Wroe, and M. R. SánchezVillagra, "Ossification heterochrony in the therian postcranial skeleton and the marsupial-placental dichotomy," Evolution, vol. 62, no. 8, pp. 2027-2041, 2008.

[33] T. Grünbaum and R. Cloutier, "Ontogeny, variation, and homology in Salvelinus alpinus caudal skeleton (Teleostei: Salmonidae)," Journal of Morphology, vol. 271, no. 1, pp. 1224, 2010.

[34] R. Cloutier, "The fossil record of fish ontogenies: insights into developmental patterns and processes," Seminars in Cell and Developmental Biology, vol. 21, no. 4, pp. 400-413, 2010.

[35] P. M. Mabee, K. L. Olmstead, and C. C. Cubbage, "An experimental study of intraspecific variation, developmental timing, and heterochrony in fishes," Evolution, vol. 54, no. 6, pp. 2091-2106, 2000.

[36] L. Fischer-Rousseau, R. Cloutier, and M. L. Zelditch, "Morphological integration and developmental progress during fish ontogeny in two contrasting habitats," Evolution and Development, vol. 11, no. 6, pp. 740-753, 2009. 
[37] P. M. Mabee and T. A. Trendler, "Development of the cranium and paired fins in Betta splendens (Teleostei: Percomorpha): intraspecific variation and interspecific comparisons," Journal of Morphology, vol. 227, no. 3, pp. 249-287, 1996.

[38] J. W. M. Osse and J. G. M. van den Boogaart, "Dynamic morphology of fish larvae, structural implications of friction forces in swimming, feeding and ventilation," Journal of Fish Biology, vol. 55, pp. 156-174, 1999.

[39] S. Herring, "Epigenetic and functional influences on skull growth," in The Skull, Development, J. Hanken and B. K. Hall, Eds., vol. 1, pp. 153-206, University of Chicago Press, Chicago, Ill, USA, 1993.

[40] B. M. Nigg and W. Herzog, Biomechanics of the MusculoSkeletal System, John Wiley \& Sons, New York, NY, USA, 1994.

[41] G. B. Müller, "Embryonic motility: environmental influences and evolutionary innovation," Evolution and Development, vol. 5, no. 1, pp. 56-60, 2003.

[42] R. J. Gomes, M. A. R. de Mello, F. H. Caetano et al., "Effects of swimming training on bone mass and the GH/IGF-1 axis in diabetic rats," Growth Hormone and IGF Research, vol. 16, no. 5-6, pp. 326-331, 2006.

[43] C. C. Lindsey, "Factors controlling meristic variation," in The Physiology of Developing Fish, Part B, Viviparity and Posthatching Juveniles, W. S. Hoar and D. J. Randall, Eds., vol. 11, pp. 197-274, Academic Press, New York, NY, USA, 1988.

[44] G. Arratia and H.-P. Schultze, "Reevaluation of the caudal skeleton of certain actinopterygian fishes. 3. Salmonidae. Homologization of caudal skeletal structures," Journal of Morphology, vol. 214, pp. 187-249, 1992.

[45] D. A. Pavlov and E. Moksness, "Reproductive biology, early ontogeny, and effect of temperature on development in wolffish: comparison with salmon," Aquaculture International, vol. 2, no. 3, pp. 133-153, 1994.

[46] D. A. Pavlov and E. Moksness, "Development of the axial skeleton in wolffish, Anarhichas lupus (Pisces, Anarhichadidae), at different temperatures," Environmental Biology of Fishes, vol. 49, no. 4, pp. 401-416, 1997.

[47] D. G. Sfakianakis, G. Koumoundouros, P. Divanach, and M. Kentouri, "Osteological development of the vertebral column and of the fins in Pagellus erythrinus (L. 1758). Temperature effect on the developmental plasticity and morpho-anatomical abnormalities," Aquaculture, vol. 232, no. 1-4, pp. 407-424, 2004.

[48] M. A. Campinho, K. A. Moutou, and D. M. Power, “Temperature sensitivity of skeletal ontogeny in Oreochromis mossambicus," Journal of Fish Biology, vol. 65, no. 4, pp. 1003-1025, 2004.

[49] C. Patterson, "Cartilage bones, dermal bones and membrane bones, or the exoskeleton versus the endoskeleton," in Problems in Vertebrate Evolution, M. S. Andrews et al., Ed., pp. 77121, Academic Press, London, UK, 1977.

[50] W. Davison, "The effects of exercise training on teleost fish, a review of recent literature," Comparative Biochemistry and Physiology - A Physiology, vol. 117, no. 1, pp. 67-75, 1997.

[51] T. Azuma, "Can water-flow induce an excellent growth of fish: effects of water flow on the growth of juvenile masu salmon, Oncorhynchus masou," World Aquaculture, vol. 32, pp. 26-29, 2001.

[52] T. Azuma, S. Noda, T. Yada et al., "Profiles in growth, smoltification, immune function and swimming performance of 1-year-old masu salmon Oncorhynchus masou masou reared in water flow," Fisheries Science, vol. 68, no. 6, pp. 1282-1294, 2002.
[53] I. Imre, R. L. McLaughlin, and D. L. G. Noakes, "Temporal persistence of resource polymorphism in brook charr, Salvelinus fontinalis," Environmental Biology of Fishes, vol. 60, no. 4, pp. 393-399, 2001.

[54] I. Imre, R. L. McLaughlin, and D. L. G. Noakes, "Phenotypic plasticity in brook charr: changes in caudal fin induced by water flow," Journal of Fish Biology, vol. 61, no. 5, pp. 11711181, 2002.

[55] S. Pakkasmaa and J. Piironen, "Morphological differentiation among local trout (Salmo trutta) populations," Biological Journal of the Linnean Society, vol. 72, no. 2, pp. 231-239, 2001.

[56] P. R. Peres-Neto and P. Magnan, "The influence of swimming demand on phenotypic plasticity and morphological integration: a comparison of two polymorphic charr species," Oecologia, vol. 140, no. 1, pp. 36-45, 2004.

[57] T. Grünbaum, R. Cloutier, P. M. Mabee, and N. R. Le François, "Early developmental plasticity and integrative responses in Arctic charr (Salvelinus alpinus): effects of water velocity on body size and shape," Journal of Experimental Zoology, Part B, vol. 308, no. 4, pp. 396-408, 2007.

[58] T. Grünbaum, R. Cloutier, and N. R. Le François, "Positive effects of exposure to increased water velocity on growth of newly hatched Arctic charr, Salvelinus alpinus L," Aquaculture Research, vol. 39, no. 1, pp. 106-110, 2008.

[59] L. Fischer-Rousseau, K. P. Chu, and R. Cloutier, "Developmental plasticity in fish exposed to a water velocity gradient: a complex response," Journal of Experimental Zoology, Part B, vol. 314, no. 1, pp. 67-85, 2010.

[60] D. L. G. Noakes and J.-G. J. Godin, “Ontogeny of behavior and concurrent developmental changes in sensory systems in teleost fishes," in The Physiology of Developing Fish, Part B, Viviparity and Posthatching Juveniles, W. S. Hoar and D. J. Randall, Eds., vol. 11, pp. 345-395, Academic Press, San Diego, Calif, USA, 1988.

[61] A. C. Gibb, B. O. Swanson, H. Wesp, C. Landels, and C. Liu, "Development of the escape response in teleost fishes: do ontogenetic changes enable improved performance?" Physiological and Biochemical Zoology, vol. 79, no. 1, pp. 7-19, 2006.

[62] G. Johnston, Arctic Charr Aquaculture, Blackwell, Oxford, UK, 2002.

[63] P. M. Mabee, "Phylogenetic interpretation of ontogenetic change: sorting out the actual and artefactual in an empirical case study of centrarchid fishes," Zoological Journal of the Linnean Society, vol. 107, no. 3, pp. 175-291, 1993.

[64] G. Dingerkus and L. D. Uhler, "Enzyme clearing of alcian blue stained whole small vertebrates for demonstration of cartilage," Stain Technology, vol. 52, no. 4, pp. 229-232, 1977.

[65] G. Arratia, H.-P. Schultze, and J. Casciotta, "Vertebral column and associated elements in dipnoans and comparison with other fishes: development and homology," Journal of Morphology, vol. 250, no. 2, pp. 101-172, 2001.

[66] P. Dagnelie, Théorie et méthodes statistiques. Applications agronomiques, vol. 1, Presses Agronomiques, Gembloux, Belgium, 2nd edition, 1977.

[67] V. D. Vladykov, "Taxonomic characters of the eastern North America charrs (Salvelinus and Cristivomer)," Journal of the Fisheries Research Board of Canada, vol. 11, pp. 904-932, 1954.

[68] J. Bouvet, "Differentiation and ultrastructure of distal skeleton of pectoral fin of indigenous trout (Salmo trutta fario L.). II. Differentiation and ultrastructure of lepidotrichia," Archives d'Anatomie Microscopique et de Morphologie Expérimentale, vol. 63, pp. 323-335, 1974. 
[69] R. L. McLaughlin and J. W. A. Grant, "Morphological and behavioural differences among recently-emerged brook charr, Salvelinus fontinalis, foraging in slow-vs. fast-running water," Environmental Biology of Fishes, vol. 39, no. 3, pp. 289-300, 1994.

[70] D. G. Sfakianakis, G. Koumoundouros, L. Anezaki, P. Divanach, and M. Kentouri, "Development of a saddlebacklike syndrome in reared white seabream Diplodus sargus (Linnaeus, 1758)," Aquaculture, vol. 217, no. 1-4, pp. 673-676, 2003.

[71] L. A. Fuiman, K. R. Poling, and D. M. Higgs, "Quantifying developmental progress for comparative studies of larval fishes," Copeia, vol. 1998, no. 3, pp. 602-611, 1998.

[72] C. H. Turner, "Three rules for bone adaptation to mechanical stimuli," Bone, vol. 23, no. 5, pp. 399-407, 1998.

[73] J. J. Mao and H.-D. Nah, "Growth and development: hereditary and mechanical modulations," American Journal of Orthodontics and Dentofacial Orthopedics, vol. 125, no. 6, pp. 676-689, 2004.

[74] N. C. Nowlan, J. Sharpe, K. A. Roddy, P. J. Prendergast, and P. Murphy, "Mechanobiology of embryonic skeletal development: insights from animal models," Birth Defects Research Part C, vol. 90, no. 3, pp. 203-213, 2010.

[75] A. W. Fiaz, J. L. van Leeuwen, and S. Kranenbarg, "Phenotypic plasticity and mechano-transduction in the teleost skeleton," Journal of Applied Ichthyology, vol. 26, no. 2, pp. 289-293, 2010.

[76] J. Stamps, "Behavioural processes affecting development: Tinbergen's fourth question comes of age," Animal Behaviour, vol. 66, no. 1, pp. 1-13, 2003.

[77] N. Danos and K. L. Staab, "Can mechanical forces be responsible for novel bone development and evolution in fishes?" Journal of Applied Ichthyology, vol. 26, no. 2, pp. 156$161,2010$.

[78] P. D. Chilibeck, D. G. Sale, and C. E. Webber, "Exercise and bone mineral density," Sports Medicine, vol. 19, no. 2, pp. 103122, 1995.

[79] A. Hosseini and D. A. Hogg, "The effects of paralysis on skeletal development in the chick-embryo: I. General effects," Journal of Anatomy, vol. 177, pp. 159-168, 1991.

[80] J. I. Rodriguez, A. Garcia-Alix, J. Palacios, and R. Paniagua, "Changes in the long bones due to fetal immobility caused by neuromuscular disease. A radiographic and histological study," Journal of Bone and Joint Surgery A, vol. 70, no. 7, pp. 1052-1060, 1988.

[81] C. Gomez, V. David, N. M. Peet et al., "Absence of mechanical loading in utero influences bone mass and architecture but not innervation in Myod-Myf5-deficient mice," Journal of Anatomy, vol. 210, no. 3, pp. 259-271, 2007.

[82] G. Ducher, C. Jaffré, A. Arlettaz, C. L. Benhamou, and D. Courteix, "Effects of long-term tennis playing on the muscle-bone relationship in the dominant and nondominant forearms," Canadian Journal of Applied Physiology, vol. 30, no. 1, pp. 3-17, 2005.

[83] G. Ducher, D. Courteix, S. Même, C. Magni, J. F. Viala, and C. L. Benhamou, "Bone geometry in response to longterm tennis playing and its relationship with muscle volume: a quantitative magnetic resonance imaging study in tennis players," Bone, vol. 37, no. 4, pp. 457-466, 2005.

[84] D. R. Carter, M. C. H. van der Meulen, and G. S. Beaupré, "Mechanical factors in bone growth and development," Bone, vol. 18, no. 1, pp. S5-S10, 1996.
[85] R. L. Young and A. V. Badyaev, "Developmental plasticity links local adaptation and evolutionary diversification in foraging morphology," Journal of Experimental Zoology, Part B, vol. 314, no. 6, pp. 434-444, 2010.

[86] J. I. Rodriguez, J. Palacios, A. Garcia-Alix, I. Pastor, and R. Paniagua, "Effects of immobilization on fetal bone development. A morphometric study in newborns with congenital neuromuscular diseases with intrauterine onset," Calcified Tissue International, vol. 43, no. 6, pp. 335-339, 1988.

[87] G. F. Weisel, "Early ossification in the skeleton of the sucker (Catostomus macrocheilus) and the guppy (Poecilia reticulata)," Journal of Morphology, vol. 121, no. 1, pp. 1-18, 1967.

[88] K. Nakashima and B. de Crombrugghe, "Transcriptional mechanisms in osteoblast differentiation and bone formation," Trends in Genetics, vol. 19, no. 8, pp. 458-466, 2003.

[89] F. Ferreri, C. Nicolais, C. Boglione, and B. Bertolini, "Skeletal characterization of wild and reared zebrafish: anomalies and meristic characters," Journal of Fish Biology, vol. 56, no. 5, pp. 1115-1128, 2000.

[90] P. Divanach, N. Papandroulakis, P. Anastasiadis, G. Koumoundouros, and M. Kentouri, "Effect of water currents on the development of skeletal deformities in sea bass (Dicentrarchus labrax L.) with functional swimbladder during postlarval and nursery phase," Aquaculture, vol. 156, no. 1-2, pp. 145-155, 1997.

[91] M. Kihara, S. Ogata, N. Kawano, I. Kubota, and R. Yamaguchi, "Lordosis induction in juvenile red sea bream, Pagrus major, by high swimming activity," Aquaculture, vol. 212, no. 1-4, pp. 149-158, 2002.

[92] P. M. Mabee, P. L. Crotwell, N. C. Bird, and A. C. Burke, "Evolution of median fin modules in the axial skeleton of fishes," Journal of Experimental Zoology, Part B, vol. 294, no. 2, pp. 77-90, 2002.

[93] M. Faustino and D. M. Power, "Development of the pectoral, pelvic, dorsal and anal fins in cultured sea bream," Journal of Fish Biology, vol. 54, no. 5, pp. 1094-1110, 1999.

[94] H. Kohno and Y. Taki, "Comments on the development of fin supports in fishes," Japanese Journal of Ichthyology, vol. 30, pp. 284-290, 1983.

[95] J. A. Velez, W. Watson, E. M. Sandknop, W. Arntz, and M. Wolff, "Larval and osteological development of the mote sculpin (Normanichthys crockeri) (Pisces: Normanichthyidae) from the Independencia Bight, Pisco, Peru," Journal of Plankton Research, vol. 25, no. 3, pp. 279-290, 2003.

[96] T. Suzuki, Y. Haga, T. Takeuchi, S. Uji, H. Hashimoto, and T. Kurokawa, "Differentiation of chondrocytes and scleroblasts during dorsal fin skeletogenesis in flounder larvae," Development Growth and Differentiation, vol. 45, no. 5-6, pp. 435-448, 2003. 

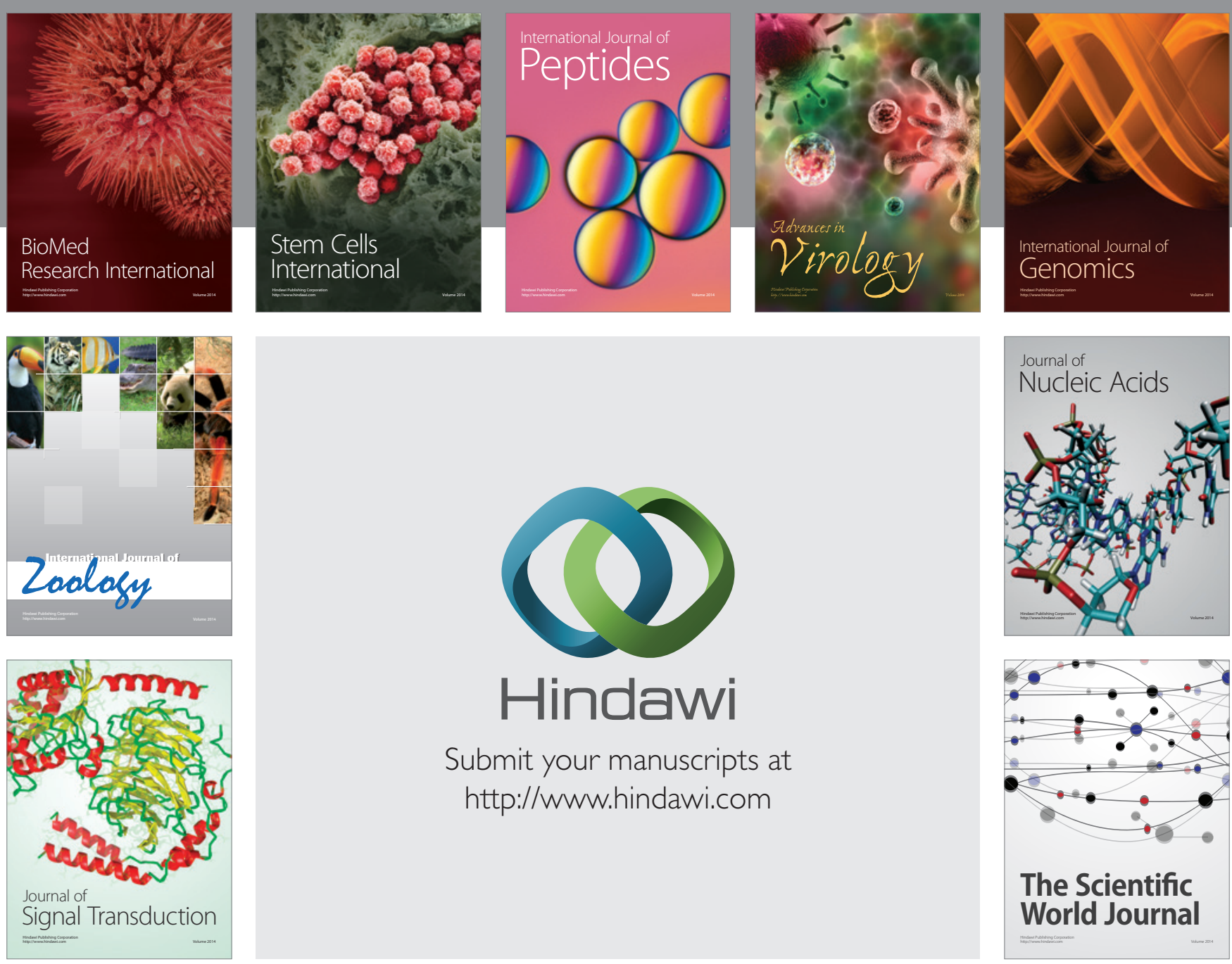

Submit your manuscripts at

http://www.hindawi.com
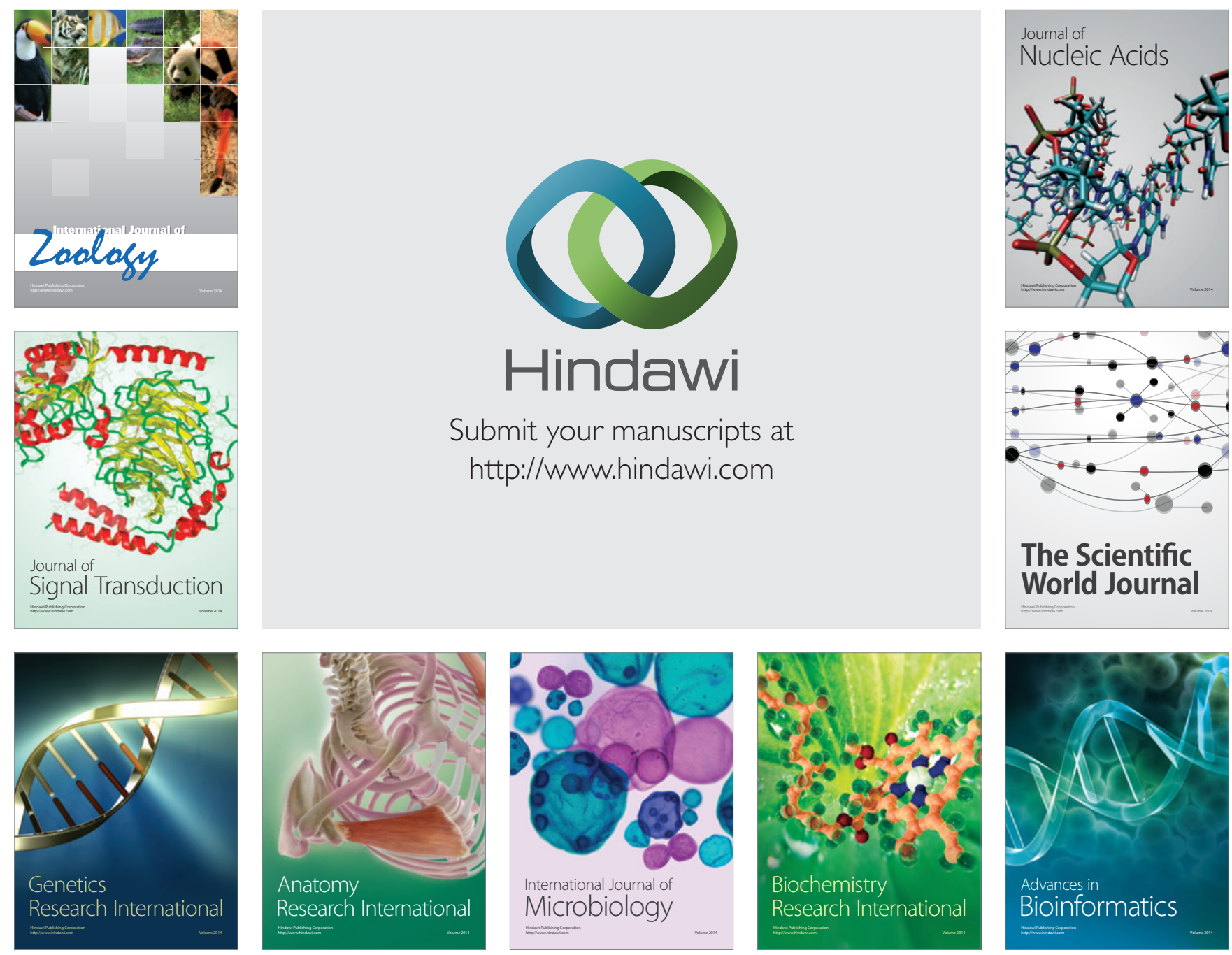

The Scientific World Journal
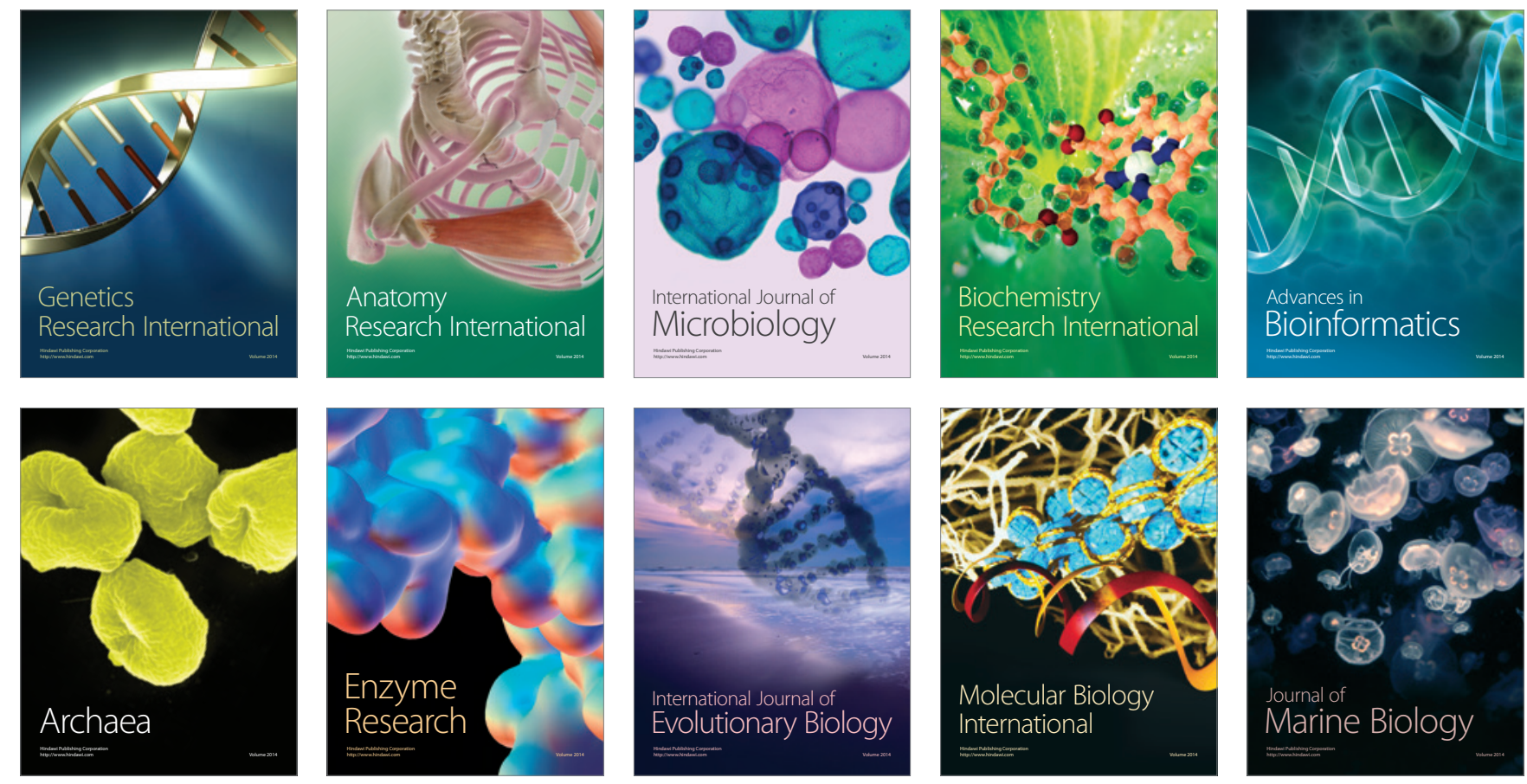